\title{
Review
}

\section{The Role of Network Science in Glioblastoma}

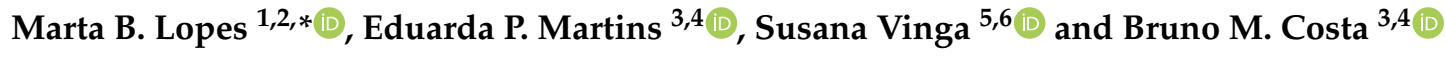 \\ 1 Center for Mathematics and Applications (CMA), FCT, UNL, 2829-516 Caparica, Portugal \\ 2 NOVA Laboratory for Computer Science and Informatics (NOVA LINCS), FCT, UNL, \\ 2829-516 Caparica, Portugal \\ 3 Life and Health Sciences Research Institute (ICVS), School of Medicine, University of Minho, Campus de \\ Gualtar, 4710-057 Braga, Portugal; id8266@alunos.uminho.pt (E.P.M.); bfmcosta@med.uminho.pt (B.M.C.) \\ 4 ICVS/3B's—PT Government Associate Laboratory, 4710-057/4805-017 Braga/Guimarães, Portugal \\ 5 INESC-ID, Instituto Superior Técnico, Universidade de Lisboa, 1000-029 Lisbon, Portugal; \\ susanavinga@tecnico.ulisboa.pt \\ 6 IDMEC, Instituto Superior Técnico, Universidade de Lisboa, 1049-001 Lisbon, Portugal \\ * Correspondence: marta.lopes@fct.unl.pt
}

Citation: Lopes, M.B.; Martins, E.P.; Vinga, S.; Costa, B.M. The Role of Network Science in Glioblastoma. Cancers 2021, 13, 1045. https:// doi.org/10.3390/cancers13051045

Academic Editors: Giuseppe Lombardi, Emilie Le Rhun,

Ahmed Idbaih, Matthias Preusser and Pim French

Received: 4 February 2021

Accepted: 22 February 2021

Published: 2 March 2021

Publisher's Note: MDPI stays neutral with regard to jurisdictional claims in published maps and institutional affiliations.

Copyright: (C) 2021 by the authors. Licensee MDPI, Basel, Switzerland. This article is an open access article distributed under the terms and conditions of the Creative Commons Attribution (CC BY) license (https:// creativecommons.org/licenses/by/ $4.0 /)$.
Simple Summary: Knowledge extraction from cancer genomic studies is continuously challenged by the fast-growing technological advances generating high-dimensional data. Network science is a promising discipline to cope with the resulting complex and heterogeneous datasets, enabling the disclosure of the molecular networks involved in cancer development and progression. We present a narrative review of the network-based strategies that have been applied to glioblastoma (GBM), a complex and heterogeneous disease, along with a discussion on the relevant findings and open challenges and future research opportunities.

Abstract: Network science has long been recognized as a well-established discipline across many biological domains. In the particular case of cancer genomics, network discovery is challenged by the multitude of available high-dimensional heterogeneous views of data. Glioblastoma (GBM) is an example of such a complex and heterogeneous disease that can be tackled by network science. Identifying the architecture of molecular GBM networks is essential to understanding the information flow and better informing drug development and pre-clinical studies. Here, we review network-based strategies that have been used in the study of GBM, along with the available software implementations for reproducibility and further testing on newly coming datasets. Promising results have been obtained from both bulk and single-cell GBM data, placing network discovery at the forefront of developing a molecularly-informed-based personalized medicine.

Keywords: network analysis; differential network expression; model regularization; causal discovery; multi-omics; biomarker selection; precision medicine; personalized therapy

\section{Molecular Networks in Precision Oncology}

The discovery and molecular characterization of cancer subtypes harboring distinct molecular features and heterogeneous treatment responses comprise a crucial step in cancer treatment and management, as different cancer subtypes may respond differently to available treatment options [1]. Similarly, the stratification of tumor cells into distinct subpopulations provides valuable insights into the molecular drivers of intratumor heterogeneity, a major issue responsible for treatment failure and drug resistance and compromising personalized-medicine approaches $[2,3]$. Remarkable advances in the field have been reached thanks to the growing availability of molecular data delivered by next-generation sequencing (NGS) technologies, which combine, for a given patient, high-dimensional data from multiple omics platforms. In most statistical and machine learning-based tools that have been proposed to this end, molecular phenotypes are treated as single, non-interacting entities in the global molecular network context. 
Network science has been widely used in the study of the topology and community structures of real-world networks [4]. In the biomedical domain, network science has emerged as a powerful tool to study biological systems governed by complex networks. Biological networks remain as one of the most studied classes of networks. Biological systems can be represented by networks, with nodes represented by distinct elements (e.g., genes, proteins, metabolites) and edges the interaction between the elements. Examples of biological networks are gene regulatory networks, gene coexpression networks, proteinprotein interaction networks, signaling, and metabolic networks. Network analysis extends the identification of individual key elements in the biological network to disclosure subnetworks within the global complex network and how they relate to function and disease. Understanding how these complex networks function has important clinical implications, in particular in the definition of molecularly-informed diagnostic, prognostic, and disease prevention strategies.

The rise of network science in cancer genomics has opened new avenues for the identification of the networks involved in cancer processes, by the identification of the molecular network structures involved in cancer development and progression. Such network-based information can be further used to drive predictive models for future outcomes to more biologically meaningful solutions, towards a more personalized clinical and therapy decision, perfectly in line with the precision medicine framework.

In this narrative review, we cover many aspects of network science and examples of applications in the study of glioblastoma (GBM), a type of cancer characterized by a marked spatial and temporal heterogeneity at both the cellular and molecular levels [5]. Among the network-based strategies proposed to model GBM molecular data, particular attention is given to critical steps in GBM molecular characterization and stratification, namely differential network analysis, gene coexpression module detection, trans-omics network discovery, cancer subtype identification, biomarker discovery, and causal inference (Figure 1). A list of the computational tools and biological databases generated from the studies covered is also provided (Table 1), as well as a summary of the key findings and major signaling pathways involved in GBM (Figure 2). For the literature search, we used an automated search via the digital libraries of two major databases (Google Scholar and Web of Science), using several search string combinations of relevant keywords. A subsequent manual selection of the relevant studies for the scope of the review was performed.

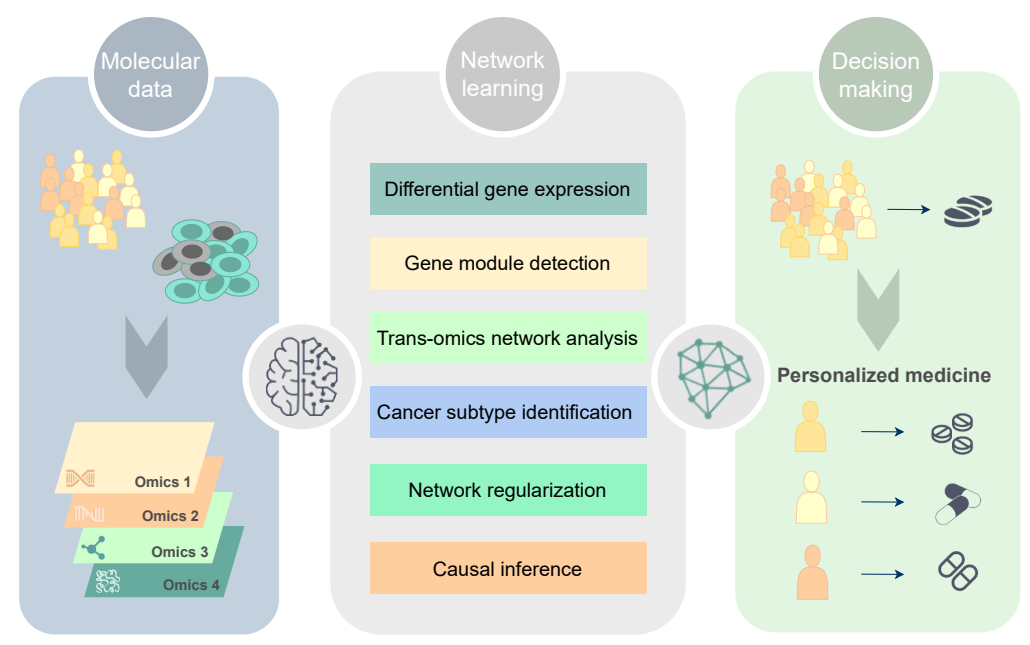

Figure 1. Overview of the current strategies in precision medicine for network learning in glioblastoma. 


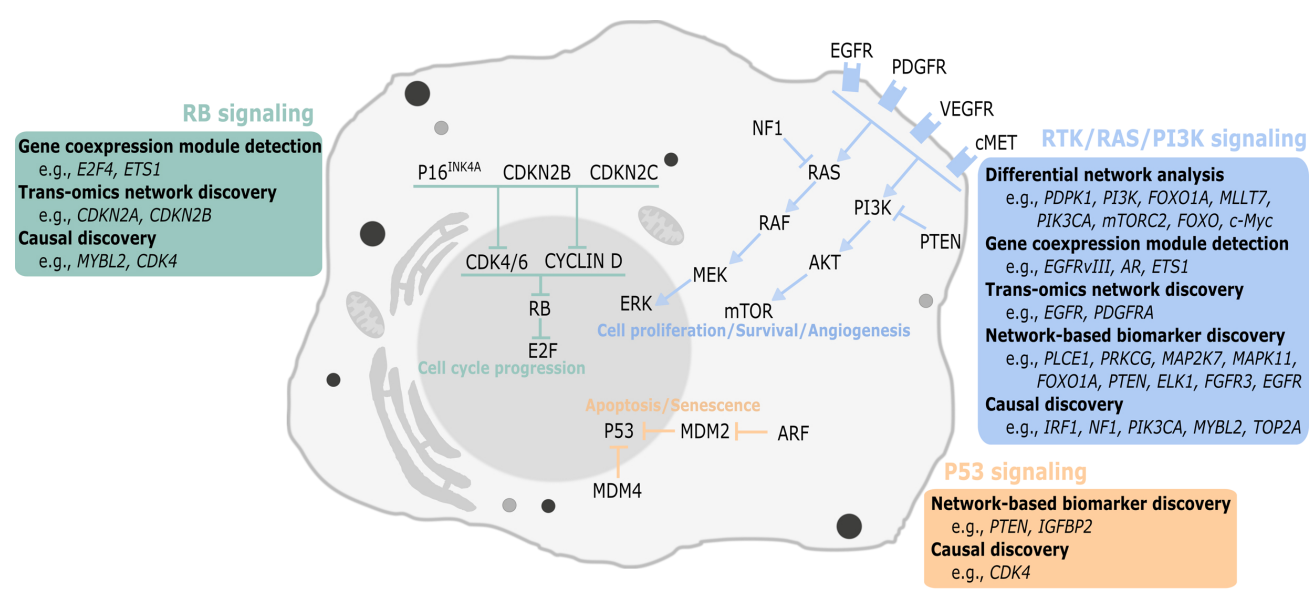

Figure 2. Simplified summary of major signaling pathways in glioblastoma and examples of genes previously identified by various network analyses.

\section{Network Discovery in Glioblastoma}

GBM is the most frequent primary malignant brain tumor in adults [1] and one of the most aggressive cancers [6,7], with a median survival of approximately 15 months after diagnosis $[8,9]$. GBM exhibits extensive tumor heterogeneity, both within and between tumors [6], which poses major challenges to diagnosis and treatment [10].

Verhaak et al. (2010) [1] performed multi-omics profiling of GBM tumors to disclose the molecular nature of GBM heterogeneity. The analysis revealed four major molecular subtypes based on transcriptomics, named classical, neural, proneural, and mesenchymal, which have recently been revised to three, classical, proneural, and mesenchymal [11]. The formerly identified neural subtype was not detected in the latter study, but it has rather been associated with tumor margin and normal neural lineage [12], probably explained by sample contamination with normal tissue in the first analysis [11]. Each identified molecular subtype is characterized by a panel of genetic alterations; in a simplistic manner, classical, mesenchymal, and proneural GBM subtypes are characterized by modifications in EGFR, NF1, and PDGFRA/IDH1, respectively [1]. This molecular classification of GBM impacts clinical outcome, as patients with primary and/or recurrent mesenchymal GBM commonly present a particularly dismal survival compared to non-mesenchymal cases [11]. Proneural GBM patients have a trend of increased survival, but do not benefit from intensive therapies, contrary to classical and mesenchymal GBMs [1]. Besides the associations between the molecular subtype and therapy response, MGMT methylation-a known predictive biomarker of response to standardized temozolomide treatment [13] — was not associated with the transcriptional subtypes [1]. Upon GBM recurrence, the majority of the cases maintained the same molecular subtype signature as the primary tumor, particularly in the case of mesenchymal GBM. This notwithstanding, a significant proportion of tumors switched molecular subtype after treatment, with an increment of proneural and mesenchymal GBMs [11]. Despite all the efforts to find similarities among the vast heterogeneity of GBMs, single-cell RNA sequencing analyses later performed by Patel et al. (2014) [10] revealed an even more complex level of heterogeneity in GBM, in which particular individual tumors contained distinct cells with transcriptional profiles resembling the various molecular subtypes firstly identified by Verhaak et al. (2010) [1]. Thus, while a predominant molecular subtype can be identified with bulk data generated at the population level, more refined single-cell sequencing analyses identify multiple clones associated with different GBM molecular subtypes in a single tumor. In addition, this study also found the existence of "hybrid" cells, i.e., individual cells with the representation of more than one subtype [11]. Interestingly and even though patients whose GBM is classified as proneural present a trend of increased survival [1], when this subtype is subdivided into pure proneural, low-heterogeneity proneural, and high-heterogeneity proneural, the increased heterogeneity of this class lowers the survival of patients, highlighting the clinical 
relevance of intratumoral heterogeneity [10]. Overall, these findings clearly highlight the remarkable level of complexity regarding the heterogeneity of GBM, potentially applicable to other cancer types. Network discovery is particularly relevant in the case of highly heterogeneous cancers, for which network-based machine learning from large-scale and multi-level NGS data at both bulk and single-cell levels is expected to provide a deeper insight into GBM's molecular mechanisms of disease development and progression.

\subsection{Differential Network Analysis}

One of the most common tasks in genomics is the identification of differentially expressed genes (DEG) across different disease conditions or cell types. This practice, although of recognized value for biomarker discovery and the development of targeted therapies, misses the overall network information genes carry while co-expressed in common regulatory pathways. To fill this gap, the differential network analysis in genomics (DINGO) model [14] (Table 1) was proposed for estimating group-specific networks and inferring differential networks. The method jointly estimates the group-specific conditional dependencies by decomposing them into global and group-specific components.

In the context of GBM, DINGO was applied to TCGA data from multiple omics platforms (mRNA expression, DNA copy number, methylation, and microRNA expression) with the goal of building differential networks for long- and short-term survivors (LTSs and STSs, respectively). The application focused on selected key signaling pathways (RTK/PI3K, p53, and Rb), involved in cell migration, survival, and apoptosis and closely associated with GBM biology.

The differential networks between GBM LTSs and STSs estimated from the different omics platforms revealed many hub genes with several important roles in GBM progression, e.g., via a connection with the $c-M y c$ gene, associated with GBM proliferation and decreased survival. Amongst the differentially expressed hub genes, PDPK1, detected in the DNA copy number network, promotes EGFR activation [15], a known driver of GBM cell proliferation, invasiveness, motility, angiogenesis, and apoptosis evasion [16], contributing to GBM's aggressiveness. PI3K genes identified from mRNA expression, DNA copy number, and methylation are frequently altered in GBM ( $88 \%$ of GBMs present alterations to the RTK/RAS/PI3K axis) [17], supporting pro-tumor effects such as proliferation, growth, differentiation, survival, and angiogenesis $[18,19]$. From the DNA methylation data, the hub FOXO1A gene was associated with MLLT7 (FOXO) and with PIK3CA (PI3K) [14]. The regulatory networks including $m$ TORC2, FOXO, and $c-M y c$ are highly intercorrelated with a shorter survival of GBM patients [20]. A previous study had already demonstrated the following connections: by acetylation, mTORC2 is able to impede FoxO activity that could surpass PI3K/AKT inhibition, upregulating c-Myc. In the clinical setting, acetylated FoxO and c-Myc were highly correlated in GBM samples, and patients expressing high levels of c-Myc showed a significantly shorter overall survival [20]. Reports on in vivo data additionally suggest c-Myc as a potential therapeutic target in GBM [21] and as an important player in PARP inhibition resistance [22]. The hubs from microRNA expression revealing a higher degree of connectivity were hsa-miR-103 and hsa-miR-107 [14], which directly interact with the CDK5R1 3'UTR [23], an activator of CDK5 [24], which is overexpressed and oncogenic in GBM [25-30]. 
Table 1. Glioblastoma databases and software tools used in the studies covered by the survey.

\begin{tabular}{|c|c|c|}
\hline Resource & Website & Ref. \\
\hline \multicolumn{3}{|l|}{ Genome projects } \\
\hline The Cancer Genome Atlas (TCGA) & https://www.cancer.gov/tcga & [17] \\
\hline Rembrandt & https://gdoc.georgetown.edu/gdoc/ & [31] \\
\hline Gene Expression Omnibus (GEO) & https://www.ncbi.nlm.nih.gov/geo/ & [32] \\
\hline NCBI Sequence Read Archive (SRA) & https://www.ncbi.nlm.nih.gov/sra & [33] \\
\hline Glioblastoma Bio Discovery Portal & https://gbm-biodp.nci.nih.gov/ & [34] \\
\hline Cancer Cell Line Encyclopedia (CCLE) & https://portals.broadinstitute.org/ccle & [35] \\
\hline Chinese Glioma Genome Atlas (CGGA) & http://cgga.org.cn/ & [36] \\
\hline \multicolumn{3}{|l|}{ Network Analysis } \\
\hline DINGO & https://cran.r-project.org/web/packages/iDINGO/ & [14] \\
\hline WGCNA & https://horvath.genetics.ucla.edu/html/CoexpressionNetwork/ & [37] \\
\hline DiME & http://www.cs.bham.ac.uk/ szh/DiME & [38] \\
\hline KINC & http://www.github.com/SystemsGenetics/KINC & [39] \\
\hline WSNF & http://nugget.unisa.edu.au/Thuc/cancersubtypes/ & [40] \\
\hline CSPRV & https://github.com/yiangcs001/CSPRV & [41] \\
\hline glmnet & https://cran.r-project.org/web/packages/glmnet/index.html & [42] \\
\hline glmSparseNet & https://bioconductor.org/packages/release/bioc/html/glmSparseNet.html & [43] \\
\hline ParallelPC & https://cran.r-project.org/web/packages/ParallelPC/ & [44] \\
\hline MSLCRN & https://github.com/zhangjunpeng411/MSLCRN & [45] \\
\hline SYGNAL & http:// www.synapse.org/\#!Synapse:syn5907990 & {$[46]$} \\
\hline inTRINSiC & https://github.com/yunpeng19071/inTRINSiC & [47] \\
\hline bnlearn & https://www.bnlearn.com/ & [48] \\
\hline Banjo & https://users.cs.duke.edu/ amink/software/banjo/ & [49] \\
\hline
\end{tabular}

\subsection{Gene Coexpression Module Detection}

Uncovering gene coexpression modules, or groups of highly coexpressed genes, has been pointed out as a promising therapy research direction for the identification and validation of novel molecular targets, through understanding of how gene modules interact with cancer lesions.

Horvath et al. (2006) [50] performed gene expression profiling on RNA from 120 GBM patient samples from two independent datasets. The identification of gene modules was performed via weighted gene coexpression network analysis (WGCNA) [37,51] (Table 1), by constructing a weighted gene coexpression network based on the pairwise Pearson correlations between the gene expression profiles, followed by an unsupervised hierarchical clustering to detect groups of highly coexpressed genes. For the first GBM dataset, the authors detected five gene coexpression modules, which were significantly enriched for genes across the ontological classes mitosis cell cycle, immune response, neurogenesis, cytoplasm, and metabolism. The same five gene modules were obtained for the second dataset, after weighted gene coexpression network construction based on the genes found for the first dataset, indicating that gene coexpression modules are highly preserved in both GBM datasets.

Among the various findings of the study, the analysis identified a mitosis/cell cycle module in GBM that is downstream of the mutant epidermal growth factor receptor, EGFRvIII, as shown by studies done in an isogenic model system. Furthermore, ASPM (abnormal spindle-like microcephaly associated) was identified as a key gene in the mitosis/cell cycle module, being associated with increased cell proliferation, underexpressed in normal tissue compared to GBM. The results also suggested ASPM's involvement in GBM pathogenesis by promoting a stem cell phenotype, therefore supporting ASPM as a potential GBM molecular target [50]. Shortly after, $A S P M$ was associated with glioma grade, showing increased expression from non-tumoral samples to grade II, III, and IV gliomas [52,53]. More recently, ASPM was also associated with the survival of patients with GBM [50,54] and glioma [55], indicating that the hub genes identified by Horvath et al. 
(2006) [50] might be new prognostic biomarkers. Interestingly, ASPM was previously identified to be expressed at higher levels in secondary GBMs as compared to lower grade astrocytomas [56] and was further validated in another study as one of the six genes with the highest relative expression in GBM compared to pilocytic astrocytomas [57]. ASPM also emerged as a hub gene in additional screening studies in GBM $[55,58,59]$, and its functional relevance was recently validated in vitro and in vivo [55]. Specifically, $A S P M$-silenced GBM cells presented decreased proliferation rates and formed in vivo subcutaneous tumors with significantly reduced sizes. Mechanistic assays suggested an association between ASPM and the Wnt / $\beta$-catenin pathway, highly relevant in GBM, and that ASPM knockdown was linked to a G0/G1 arrest of GBM cells [55]. Globally, this is a paradigmatic example on the use of network analysis that allowed the identification of a novel GBM biomarker, with critical oncogenic functions and prognostic clinical potential, for which novel smart therapies can be developed in the future.

Since it was first proposed, WGCNA has been extensively applied in subsequent studies on the gene coexpression relationships across glioma subtypes to identify key genes and pathways associated with the occurrence, progression, and survival of GBM (e.g., [60-68]).

Disease module extraction (DiME) is another algorithm to identify disease modules from biological networks [38] (Table 1), built up the community extraction (CE) module criterion originally proposed for social network analysis [69]. In a study of the molecular mechanisms involved in glioma progression, Liu et al. (2014) [38] developed novel heuristics to optimize CE and incorporated the B-score, a measure of statistical significance, to evaluate the quality of the modules extracted from low- (grade II) and high-grade (GBM) glioma co-expression networks.

The datasets used consisted of microarray expression data from 97 grade II patients and 126 GBM samples, retrieved from the Rembrandt database (Table 1). Further validation was performed on the TCGA GBM dataset and the grade II glioma expression dataset (GSE30339) from the Gene Expression Omnibus (GEO) database (Table 1), consisting of 197 and 23 samples, respectively. From grade II gliomas to GBM, a shift in network topology was observed, with GBM tumors showing altered levels of transcripts involved in extracellular matrix (ECM) reorganization and angiogenesis, which stand as markers of a more aggressive phenotype. The analysis also identified several statistically significant modules that were reproducible across the different datasets, from which the transcription factors $E 2 F 4, A R$, and ETS1 are highlighted as potential key regulators in tumor progression. E2F4 is overexpressed in high-grade gliomas (HGGs) and is associated with poorer survival outcome [70]. Interestingly, AR was later found overexpressed in GBMs [71-73] and associated with poor survival of patients with low-grade gliomas (LGGs) [72]. A growing body of evidence also suggests AR as a modulator of treatment response in GBM, for example: (i) AR confers radiation resistance [73]; (ii) the nuclear translocation of AR is affected by cedrol treatment, suppressing GBM progression [74]; (iii) the $5 \alpha$-reductase enzyme inhibitor dutasteride in combination with AR antagonists effectively decreased the proliferation of GBM cells [75]; and (iv) a curcumin analog induced the ubiquitination of $\mathrm{AR}$ and consequent degradation, suppressing the growth of temozolomide-resistant cells [76]. Similarly, ETS1 had also been studied for its impact in the expression/regulation of other genes in brain tumors, such as $u P A$ and Flt-1/VEGFR-1 in astrocytic tumors $[77,78]$ and DPP-III when conjugated with Elk-1 in human GBM [79]. More recently, ETS1 was also found to transcriptionally activate the C250T mutant form of the TERT promoter [80], which has been recognized as a critical driver of replicative immortality in GBM [81,82].

To identify gene expression relationships across multiple human tumors, Dunwoodie et al. (2018) [83] used the Knowledge-Independent Network Construction (KINC) software [39] (Table 1) to build two RNAseq-based gene coexpression networks based on publicly available datasets from TCGA (GBM; LGG; bladder urothelial carcinoma; thyroid carcinoma; and ovarian serous cystadenocarcinoma) and the NCBI Sequence Read Archive (SRA) (GBM, normal brain, and Parkinson's brain) (Table 1). KINC uses Gaussian mixture 
models (GMMs) before applying pairwise correlation analyses to the gene expression matrices. The major feature of KINC is its ability to deconvolute mixed-condition expression patterns (e.g., mixed tumor expression profiles from GBM and non-GBM samples) without the need to separate gene expression profiles before analysis.

A 22-gene GBM-specific module was identified in the two gene expression sources. The module showed increased RNA expression compared to normal brain and LGG samples and decreased DNA methylation in GBM in relation to LGG. Moreover, seventeen of the 22 shared genes were found in the Glioblastoma Bio Discovery Portal (GBM-BioDP) (Table 1) based on results from Verhaak et al. (2010) [1]. The highest expression for these genes was observed for the mesenchymal subtype, and high expression was associated with decreased survival in each GBM subtype. Four genes (SIGLEC9, MYO1F, LAPTM5, ITGB2) from the 22 gene list were upregulated in mesenchymal GBM. Interestingly, recent data indicated ITGB2 as being highly positively correlated with the tumor-associated macrophage (TAM) marker CD68 [84], suggesting an increased infiltration of TAMs in ITGB2-positive gliomas. Furthermore, higher expression of ITGB2 was associated with shorter overall survival of glioma patients [84]. These data are in agreement with the study of Wang et al. (2017) [11], in which the authors identified an increment of infiltrating macrophages in mesenchymal GBMs and shorter survival of this subtype [11].

\subsection{Trans-Omics Network Discovery}

The rapid advances in sequencing technologies have enabled the acquisition of patient molecular information by diverse omics assays. With the great amounts of molecular information generated per patient, it became possible to explore the relationships among molecular features across different omics layers, e.g., DNA variants and downstream phenotypes, and potentially identify trans-omics therapeutic targets.

The first method we showcase extends DINGO (Section 2.1) to integrate matrices of expression data on the same samples from different platforms (iDINGO) [85] for a deeper biological understanding of the relationships across the omics layers. The method estimates group-specific dependencies and makes inferences on the integrative differential networks, considering the biological hierarchy among the platforms.

Jörnsten and co-authors (2011) [86] addressed the challenge of uncovering how DNA copy number aberrations (CNAs) affect gene expression, via endogenous perturbation analysis of cancer $(\mathrm{EPoC})$, a method that constructs mRNA-based network models in which mRNA patient profiles are regarded as responses to perturbations induced by CNAs during tumor evolution. The goal is to detect disease-driving CNAs, assess their effect on target mRNA expression, and disclose GBM biomarkers, which are predictors of patient survival.

To identify the transcriptional and CNA-mRNA couplings, EPoC solves the two complementing linear systems, one representing the transcriptional interaction network and the other the CNA-driven network, consisting of CNA-mRNA interactions. EPoC first uses a combination of lasso regression and bootstrapping to estimate the parameters of the EPoC network model from paired DNA- and RNA-level data. Then, a score based on sparse singular-value decomposition of the derived CNA-mRNA network model is computed to disclose prognostic biomarkers able to stratify patients into LTSs and STSs.

The method was applied to TCGA GBM datasets (CNA and mRNA), based on 10,672 genes and 186 patients. Known disease-driving CNAs controlling multiple downstream hub genes could be identified, namely oncogenes and tumor suppressors with a known role in GBM, including EGFR, PDGFRA, CDKN2A, and CDKN2B, but also other interesting hub genes not previously associated with GBM, e.g., MTAP and SEC61G. The model also detected robust CNA-mRNA links between the hubs EGFR, PDGFRA, and $C H I C 2$ and markers of early neural development, such as a GBM stem cell marker, CD133 (PROM1), and the transcription factors SOX10, SOX11, NR2E1 (TLX), and NKX2.2. From all these pinpointed genes, the impact of MTAP, SEC61G, CD133, and SOX11 was previously evaluated in GBM patients. MTAP has been implicated as a prognostic factor, despite discordant findings: MTAP deletion was associated with decreased progression- 
free survival in GBM patients [87], while another study reported that adult GBM patients lacking MTAP expression had better survival than those with detectable levels of MTAP expression [88]; SEC61G's higher expression was linked to decreased overall survival of patients from TCGA [89]; SOX11 overexpression was reported to be associated with longer overall survival $[90,91]$; finally, the impact of CD133 in patient prognosis is quite controversial, but a recent meta-analysis of published data concluded that higher expression of CD133 is associated with poorer prognosis [92]. The results obtained by the CNA-driven GBM network model were further validated in four GBM cell lines (T98G, U-87MG, U$343 \mathrm{MG}$, and U-373MG), via perturbations on $N D N$, which encodes the p53-interacting protein necdin, to suppress GBM cell growth. In the resulting CNA-driven network, NDN shares a target, fibroblast growth factor 9 (FGF9), with PDGFRA, which is frequently amplified in GBM.

Multiple microRNAs (miRs) have been described as promoting or suppressing oncogenesis, as modulators of gene expression. Genovese et al. (2012) [93] inferred putative GBM regulatory networks between miRs and mRNA GBM data using the context-likelihoodrelatedness (CLR) [46] algorithm. The dataset counted for 290 matched miR and mRNA expression profiles, yielding a total of 26,297 edges between $254 \mathrm{miR}$ and $6152 \mathrm{mRNA}$.

CLR generates pair-wise associations based on mutual information (MI). The algorithm involves a statistical background correction step, in which the significance of each miR-mRNA MI value is assessed against the background distribution of MI scores for all possible $\mathrm{miR} /$ gene pairs that include either the miR or its target. After this background correction, the most probable interactions are those whose MI scores stand signficantly above the background distribution of MI scores. The analysis suggested a role of mRNA regulation by $\mathrm{miR}$ in the definition of the molecular proneural and mesenchymal subtypes, revealed by the marked expression differences in the edges obtained for the global network between these subtypes. miR-34a expression was found to be prognostic in GBM, in both TCGA and an independent cohort of human gliomas, with miR-34a low-expressing GBM patients exhibiting an overall improved survival. The same results were obtained for the proneural subtype. Evidence of $m i R-34 a$ as a tumor suppressor in proneural GBM was also obtained by integrative in silico analyses, functional genetic screening, and experimental validation [93]. A direct regulation of PDGFRA by $m i R-34 a$, previously found as functionally related to proneural GBM [94], was also confirmed. Additionally, promoter enrichment analysis of the edges identified uncovered a novel regulation of TGF $\beta$ signaling via a Smad4 transcriptomic network by miR-34a [93], later shown to be implicated in the regulation of GBM cells' migration and invasion [95].

\subsection{Network-Based Learning}

\subsubsection{Cancer Subtype Identification}

Cancer genomic profiling has been extensively used to stratify cancer samples into well-characterized molecular subtypes towards improved diagnosis and prognosis. The increasing availability of information from biological networks from multiple molecular assays has motivated researchers to incorporate such invaluable information into the learning procedure.

Xu et al. (2016) [40] addressed the problem of identifying cancer subtypes, by developing the weighted similarity network fusion (WSNF) method (Table 1). WSNF is based on a previously proposed method, similarity network fusion (SNF) [96], a multi-omics data fusion method that stratifies patients into cancer subtypes based on a fusion similarity matrix obtained from the similarities between patients from different data types and a subsequent clustering step. WSNF extends SNF to make use of available information on biological networks, such as gene regulatory networks, by incorporating feature weights (i.e., feature importance) into the clustering process for cancer subtype identification from multi-omics data, which are obtained by combining features' ranking in the network and their expression variation. 
In an application to the TCGA GBM dataset, WSNF was built on gene expression data and information from a complex miRNA-TF-mRNA regulatory network, with the nodes representing the features, i.e., miRNA, transcription factors (TF), and mRNAs, and the edges of the interactions between them, the latter retrieved from interatomic databases. In this study, WSNF was able to identify three GBM subtypes with significantly different survival patterns and enriched pathways.

GBM subtype identification was also approached via CSPRV (cancer subtype prediction using $R V_{2}$ ) [41], a method that overcomes previous methods also integrating multi-source transcriptome expression and biological networks for cancer subtype prediction, by considering the data-view weights in data integration, the importance of features, and their relationships in data integration. CSPRV is a multi-step procedure that first extracts multiple expression features of each regulatory element based on the regulatory associations in the biological networks; then, it reduces the high-dimensional expression features extracted to a low-dimensional space and constructs an integrative feature matrix for each sample; it uses a matrix correlation method, $R V_{2}$ [97], to predict the similarities between samples in each expression data-view, which are then fused according to the different integration weights; and finally, it clusters samples into different groups based on the integrated similarities between samples. CSPRV showed improved performance in the identification of GBM subtypes with different survival patterns over WSNF.

\subsubsection{Model-Based Biomarker Discovery}

One of the biggest challenges in the identification of predictive models for cancer outcomes and key drivers of disease processes is the problem of the high-dimensionality of molecular data matrices. The incorporation of model regularizers in generalized linear regression frameworks has shown promise in both predictive model performance and feature selection across many biomedical contexts (see [98]). These include the least absolute shrinkage and selection operator (lasso) [99], elastic net [100], fused lasso [101], along with variants such as adaptive lasso [102] and group lasso [103]. However, these strategies rely solely on data and the computational aspects of algorithm implementation, without incorporating any prior information on the biological processes.

The remarkable technological advances in the last few decades and great efforts of large consortia, e.g., through genome- and proteome-wide projects, have produced a vast amount of molecular and pathway information now available through biological databases (Table 1). Regulatory networks can be represented by graphs, where the nodes or vertices represent the genes or gene products and the edges the relationships among them. To take advantage of such a massive amount of valuable information, several methods have been proposed to incorporate information from these graphs, e.g., pathway topology, into model generation, leading to more interpretable solutions.

$\mathrm{Li}$ and $\mathrm{Li}$ (2008) [104] introduced a network-constrained penalty function to identify genes and subnetworks that are related to phenotype responses. The regularizer penalizes the $\ell_{1}$-norm (lasso) of the coefficients while encouraging the smoothness of the coefficients on the network through a graph Laplacian constraint. The proposed network-constrained procedure was applied to a GBM microarray gene-expression dataset [104] on 50 patients and 1533 genes found in the Kyoto Encyclopedia of Genes and Genomes (KEGG) network of 33 pathways. The method was successful in the identification of subnetworks of the KEGG pathways that were related to patient survival from GBM, some of them supported by previous studies. Among the subnetworks identified, the largest included genes involving the MAPK signaling pathway (e.g., PLCE1, PRKCG, MAP2K7, ZAK, KBKG, TRAF2, and $M A P K 11)$ and its connected pathways, such as the PI3K/Akt signaling pathway (e.g., gene GYS1) and its target FOXO1A $[105,106]$. Another subnetwork identified four genes, PTEN, PRKG2, MAPK8IP2, and ELK1. PTEN is a negative regulator of PI3K signaling [107,108], frequently dysregulated in GBM; the PRKG2 gene encodes cyclic guanosine monophosphate (cGMP)-dependent protein kinase II and is responsible for anti-proliferative signals in human gliomas [109]; the MAPK8IP2 gene encodes a JNK-interacting protein, influenc- 
ing JNK and p38MAPK signaling [110], which are pivotal in GBM [111,112]; and ELK1 is a downstream target of $\mathrm{PKC} \eta-$, and its activation results in increased proliferation in GBM cell lines [113]. The gene pairs subnetworks also revealed genes with a previously reported role on GBM, namely the CTNNB1 [114,115], CTLA-4 [116], and CLDN gene families [117,118].

Other strategies for accounting for network-based information during the learning process encompass the introduction of weights in the coefficients, which can be derived either from the network topology of external databases (e.g., protein-protein interaction databases) or of the data network structure itself, e.g., the correlation/covariance matrices, as shown in survival and classification on breast, melanoma, and ovarian cancer datasets [42,43,119-121], using available implementations in the R packages glmnet [122] and glmSparseNet [42] (Table 1). Considering the elastic net regularizer, this is equivalent to adding a weight factor to the penalty term.

Under the regularized-based learning framework, a variant of the above correlationbased regularizers, the twin networks recovery (twiner) penalty was introduced by Lopes et al. $(2020)[123,124]$ to explore the differences in the gene correlation networks in a classification setting. Given two disease types, the goal is to select features that have a similar correlation pattern across the two conditions, which can be regarded as putative disease targets for the development of shared therapeutic approaches for the two diseases. The twiner regularization weights are built based on the similarities given by pairwise correlations between the variables independently obtained from two given datasets (disease types/conditions). For a given variable (gene), the lower the distance between the correlation vectors in the two disease conditions, the lower the penalty induced on that gene. These ideas have been recently extended to survival modeling via the TCox [125], intended to select variables with distinct correlation patterns across two group conditions, e.g., cancer vs. normal tissue, which have a relation to the survival outcome.

The suitability of the above network-based regularizers has been shown to be promising when tackling GBM heterogeneity via biomarker selection and classification [123] in a single-cell RNA sequencing (scRNA-seq) GBM dataset [126]. The authors proposed a classification setting through sparse logistic regression to classify cells into different populations (neoplastic and normal cells), while selecting gene features discriminating between classes, but also those shared by different neoplastic clones (tumor core and infiltrating cells), standing as putative therapeutic markers to target multiple clones.

Among the genes revealed by the analysis, several have a known role in GBM, in particular: three upregulated genes in GBM infiltrating tumor cells with known functions involving the invasion of the interstitial matrix, ATP1A2, PRODH, and FGFR3 [126]; the epidermal growth factor receptor $(E G F R)$, upregulated in neoplastic periphery astrocytes and significantly mutated in GBM $[127,128]$; $A N X A 1$, upregulated in infiltrating astrocytes, promoting GBM tumor growth and progression [129] and correlated with IGFBP2, also selected and upregulated in GBM; the serine protease HTRA1, downregulated in neoplastic periphery astrocytes, a binding partner of the macrophage migration inhibitory factor (MIF) [130]; SOX9 and EGFR, associated with astrocyte development and differentiation; CHCHD2, showing coamplification with the well-known GBM marker, EGFR, in glioma [131,132]; the transcriptomic factor SOX9, involved in brain development and lineage specification, with an established oncogenic role in gliomas [126,133]; PSAP, a target for glioma treatment, by promoting glioma cell proliferation via the TLR4/NF-kB signaling pathway [134]; PREX1 and $A B H D 2$, shown to promote tumor invasion and progression in GBM [135]; and the tumor suppressor BIN1, regulated by HNRNPA2B1 and a putative proto-oncogene in GBM [136]. The relevance of the genes identified was confirmed by their significance in the survival outcomes from a bulk GBM RNA-seq dataset (TCGA), as well by their association with several Gene Ontology (GO) biological process terms. 


\subsection{Causal Discovery}

The discovery of the causal relationships in complex molecular networks is a challenging problem that has recently attracted many researchers in the field of cancer genomics, to overcome the fact that measures of association do not reveal the direction of the estimated association. The identification of causal relationships within molecular paths is crucial to unveil cancer disease dynamics and therapeutic targets.

Zhang and co-authors (2018) [45] extended module detection and trans-omics network discovery (see Sections 2.2 and 2.3) to disclose the causal role of long non-coding RNAs (lncRNAs) on messenger RNAs (mRNAs). lncRNAs interact with mRNAs through gene regulatory networks to carry out biological functions, such as cell differentiation, cell proliferation, and cytoprotective programs [137]. The authors proposed module-specific lncRNA-mRNA causal regulatory networks (MSLCRN) (Table 1), a method aimed at inferring and analyzing module-specific lncRNA-mRNA causal regulatory networks.

MSLCRN is a three-step procedure to infer module-specific IncRNA-mRNA causal regulatory networks. The method first identifies lncRNA-mRNA coexpression modules using WGCNA [37]. Second, the causal effect of IncRNA on mRNA in the causal pairs in each module identified is estimated using the intervention calculus when the DAG is absent (IDA) algorithm [138], in two steps: (i) using the parallel-PCalgorithm [44,139] (Table 1), a parallel version of the PC algorithm [140], to learn the causal structures, or directed acyclic graphs (DAGs), where the nodes are the lncRNAs or mRNAs and the edges between two nodes represent the causal relationship between them; and (ii) estimating the causal effects of lncRNAs on mRNAs by applying do-calculus [141]. A global lncRNA-mRNA causal regulatory network was finally identified, by integrating the module-specific lncRNA-mRNA causal regulatory networks.

In an application of MSLCRN to matched expression data of 9704 lncRNAs and 18,282 mRNAs in 451 GBM samples [142], twenty-three lncRNA-mRNA causal regulatory networks were identified. In subsequent Gene Ontology (GO) and KEGG enrichment analyses to assess the biological meaningfulness of the MSLCRN networks identified, fifteen out of the $23(65.2 \%)$ networks were found significantly enriched in at least one GO biological process or KEGG pathway.

Plaisier et al. (2016) [143] developed the TF-target gene interaction database and the Systems Genetics Network Analysis (SYGNAL) pipeline (Table 1), for dissecting GBMrelated causal transcriptional regulatory networks (TRNs) and predicting drug targets, based on multi-omics and clinical patient data. The SYGNAL pipeline uses correlative, causal, and mechanistic inference approaches to infer the causal flow from mutations to regulators (TFs and miRNAs) and their downstream target genes.

The authors hypothesized that a TRN describing TF-miRNA regulatory interactions would be helpful for prioritizing combinatorial interventions and drive therapeutic research to the development of therapies targeting TFs and miRNAs. Such a TRN is potentially more effective than single TF and miRNA targeted therapies, by the regulation of several genes involved in diverse oncogenic processes. The SYGNAL pipeline was applied to the multiomics TCGA GBM data. The resulting gbmSYGNAL network predicted 67 novel regulators (TFs and miRNAs) associated with patient survival or oncogenic processes. Among the relevant findings of the gbmSYGNAL network, the network revealed modulation of IRF1 by mutated NF1 and PIK3CA to increase tumor lymphocyte infiltration.

More recently, Liu and co-workers (2020) [47] developed a computational pipeline, Integrative Modeling of Transcription Regulatory Interactions for Systematic Inference of Susceptibility in Cancer (inTRINSiC) (Table 1), to dissect the TF regulatory circuitry underlying the heterogeneity of GBM based on the integration of epigenomic, transcriptomic, protein interaction, and genetic perturbation. The inTRINSiC pipeline runs in two main steps. The first step encompasses procedures for constructing context-specific regulatory networks that readily accommodate additional mechanisms of transcription regulation. In the second step, context-specific networks are used to perform in silico perturbation 
analysis and infer the dependency on TFs by each subtype, through simulation of the information flow from the TF regulation layer to the protein signaling layer.

The platform was applied to sample data from the Cancer Cell Line Encyclopedia (CCLE) [35], TCGA, and the Chinese Glioma Genome Atlas (CGGA) project (Table 1), enabling the identification of the differential regulatory activity of TFs across different GBM subtypes. In the subsequent in silico perturbation analysis, the authors identified $M Y B L 2$, a member of the $M Y B$ family of transcription factors associated with cell cycle progression and maintenance of cells in an undifferentiated state [144], as a transcription factor essential for the proneural subtype, affecting patient survival, in which patients with low MYBL2 expression showed significantly longer survival [47].

Bayesian networks (BNs) are a type of directed acyclic graph (DAG), where each node is a random variable and each edge represents a conditional probabilities relationship between a given pair of nodes. BNs can be used to infer regulatory networks, through the identification of the conditional probabilities, which in turn can be used to infer the direction of information flow within the network and hypothesize putative underlying causal relationships between the nodes. Kaiser et al. (2017) [145] used Bayesian inference to disclose changes in the extracellular regulatory network related to host immunity and co-occurring with oncogenesis, such as an increase in cell proliferation and epithelialto-mesenchymal transition (EMT). The authors used TCGA gene expression data from tumor and normal breast cancer tissue samples, combined with defined gene signatures, the metagenes, which represented groups of genes, instead of single genes, associated with the processes of interest, either immune or cancer related. Although the study was developed for breast cancer data, the authors investigated other cancer types, namely GBM, to determine whether the relationships inferred were breast cancer-specific or not.

The Bayesian networks were generated from the metagene constructs using an incremental associated Markov blanket (IAMB) algorithm [146] implemented in the bnlearnR package (Table 1). The IAMB algorithm starts with a forward phase that generates a network by maximizing the conditional independence of the nodes, followed by a backward phase that removes one-by-one any remaining conditionally independent connections. The use of metagene constructs was intended to simplify the DAG, by reducing the dimension to a low number of less computationally expensive and interpretable nodes, and help eliminating noise in the data. Confidence for the edges was calculated using a bootstrap resampling strategy, by randomly sampling patient data with replacement, with a network generated from the new dataset in each replicate.

In the resulting breast and GBM networks, increased proliferation led to increases in M1 polarized macrophages associated with increases in natural killer cell infiltration in GBM. When using only cancer samples, however, the relationship between EMT and macrophage polarization in the network reemerged. The authors reasoned that these differences might be related to the fact that GBM arises in an immune-privileged area.

Kunkle et al. (2013) [147] developed a meta-analysis of 12 microarray studies on normal and astrocytoma tissues, followed by a Bayesian analysis of the results of this meta-analysis. The goal was to identify key genes and/or pathways in the development of astrocytic tumors. The analysis pipeline involved the identification of a significant set of de-regulated genes across the microarray studies considered, enrichment and network analyses of the significant genes and investigation and validation of the network analysis.

The Bayesian networks were inferred using the Banjo (Duke University, NC) software (Table 1), which performs Bayesian structure inference based on Dirichlet scoring. The Bayesian network genes in each stage of astrocytoma (grades I-IV) were used to identify key genes in the development of astrocytoma, through the identification of a set of Markov blanket genes from each gene network, which stands, for a given node, as the set of the parents, children, and the children's parents. In the resulting GBM (grade IV) network inferred, the most influential genes, COL4A1, EGFR, BTF3, MPP2, RAB31, CDK4, CD99, ANXA2, TOP2A, and SERBP1, were able to accurately predict non-tumor and tumor cases [147]. Some of those genes have been reported to be highly expressed or activated 
in GBM, e.g., EGFR [17], BTF3 [148], CD99 [149,150], TOP2A [151], and SERBP1 [152]. Moreover, the analysis of gene-gene interactions revealed joint effects of changes in the expression of Markov blanket genes in the risk for developing GBM, which was dramatically increased with joint effects of four to 10 Markov blanket genes, resulting in a 9 to $85.9 \%$ increase, respectively, compared to the normal population [147].

In the BN research vein as well, Cai et al. (2019) [153] proposed a tumor-specific computational framework based on Bayesian causal modeling, tumor-specific causal inference (TCI), to estimate the causal relationships between somatic genome alterations (SGAs) and molecular phenotypes (e.g., transcriptomic, proteomic) observed in an individual tumor. TCI integrates multiple types of SGAs and molecular phenotypes to estimate which genome perturbations are causally influencing one or more molecular/cellular phenotypes in an individual tumor. TCI was applied to 5097 tumors across 16 cancer types in TCGA, including GBM, to derive tumor-specific causal network models. TCI identified 634 causative SGAs of cancer-related DEGs in a significant number of tumors. TCI inferred statistically robust causal relationships, which were further supported by computational and experimental analyses.

In another branch of causal discovery, Mendelian randomization (MR) uses genetic variants, such as single-nucleotide polymorphisms (SNPs), that are robustly associated with an exposure as proxies for the risk factor of interest [154], therefore eliminating confounding and reverse causation effects between the exposure of interest and outcome. Howell et al. (2020) [155] used MR to assess the causal relationship of associations of 36 reported glioma risk factors obtained from a systematic MEDLINE search on observational epidemiology studies. A meta-analysis of two glioma genome-wide association studies (GWASs) was then performed, and a two-sample MR analysis using the GWAS exposure and outcome datasets investigated the causal relationships between the risk factors identified and glioma incidence. The MR analysis revealed that four genetically predicted traits increased the risk of glioma, GBM, or non-GBM, namely longer leukocyte telomere length, liability to allergic disease, increased alcohol consumption, and liability to childhood extreme obesity. On the other hand, two traits, increased low-density lipoprotein cholesterol (LDLc) and triglyceride levels, decreased the risk of non-GBM cancers.

\section{Major Challenges and Future Strategies}

The enormous quantity of multi-omics data generated in recent cancer-related studies and the software tools able to perform network analyses portrayed in this review must be further explored, integrated, and made available to wider audiences. It is still crucial to better identify which genes involved in a particular network are truly clinically relevant. As denoted by the authors that developed the WGCNA software, the large list of hub genes identified in the analysis might be further shortened based on some filtering strategies, such as the availability of protein biomarkers and mouse models for validation, biological relevance based on ontology data, and the capacity to be used as a therapeutic target [50]. The information gathered from network analyses is expected to help in the prediction of tumor characteristics and, ultimately, assist in precision medicine approaches that might influence clinical decisions.

Having in mind the tremendous effect that these data can have in the clinical setting, the need for validation of the utility of particular networks is undeniable. Studies from Horvath et al. (2006) [50] perfectly described the workflow of the identification of a network to the clinical validation, from bioinformatics analyses to in vitro studies and the search for clinical significance. This study led to the identification of the ASPM gene [50], and its relevance was further validated both by the same authors and in other groups [50,55], as detailed in Section 2.2. Similarly, the functional relevance of SERBP1, identified in a Bayesian network [147], was further evaluated by an independent study [152]. 
The validation of molecular networks might be performed by testing key genes in genetically-manipulated GBM models, combined with pharmacological approaches for the activation/inhibition of the target, using both cell lines and patient-derived cultures, to evaluate functional effects and omics alterations. Complementing in vitro findings with in vivo models of GBM, including syngeneic and xenograft mice models, is also of critical translational relevance. In the last few decades, some novel in vitro and in vivo models have emerged, which attempt to surpass some of the limitations and simplicities of homotypic in vitro cultures with GBM cell lines. For example, organoids with heterotypic cultures can be grown from a patient tumor tissue and be used for therapy response evaluations [156]. Different studies showed that GBM organoids better recapitulate the parental tumor, maintaining the critical cellular and molecular heterogeneity and mutational profiles of particular tumor niches $[157,158]$. Beyond these advantages, organoids also allow the establishment of heterotypic cultures, in which non-tumor cells (i.e., immune cells, endothelial cells, etc.) that are commonly present in the original tumor can be co-cultured with exogenous cells, better mimicking the tumor microenvironment [159]. At the in vivo level, patient-derived xenografts (PDXs), in which a patient tumor is directly implanted in immunodeficient mice, have also emerged as a promising approach to better reflect the various aspects of tumor pathophysiology, heterogeneity, and response to therapy [160-162]. Orthotopic PDXs of GBM have been shown to preserve tumor morphology, invasion patterns, and critical molecular aberrations, such as alterations of TERT, EGFR, PTEN, TP53, BRAF, and IDH1. On the contrary, necrosis and microvascular proliferation seem to be lost upon engraftment, as is the case for some molecular alterations, including PDGFRA amplification [163]. PDXs represent excellent models to study and/or validate molecular networks, as they better maintain GBM heterogeneity and predict therapy responses. In fact, recent studies have been trying to find correlations between genotypic profiles/signatures and the response to standardized treatments of GBM using PDXs $[164,165]$. Another recent innovation is related to liquid biopsies in the context of cancer, in which cancer-relevant biomarkers are assessed in body fluids (e.g., blood, urine, cerebrospinal fluids, and ascites) [166,167]. Contrary to tumor tissue biopsy, liquid biopsies are noninvasive, allowing more frequent sample collection and monitoring of the tumor evolution longitudinally $[2,168]$. In particular for gliomas, the majority of studies have used blood samples and cerebrospinal fluid, and a residual number of reports evaluated urine samples [169]. Miller et al. (2019) [170] identified a genomic landscape of glioma based on cerebrospinal fluid that resembled the primary tumor, highlighting how liquid biopsies could be used to track glioma. Considering the intra- and inter-tumor heterogeneity of GBM, and its evolution, future studies should critically focus on how network analyses might assist the evaluation of omics data generated from liquid biopsies, which may facilitate and improve the level of examination of tumor dynamics, better predicting tumor progression and therapy responses. Molecular network models will also be pivotal in (near) single-cell analyses [171], depicting the multiple genetic patterns of individual cells that constitute a single tumor, potentially aiding in the selection and development of anti-GBM targeted therapies that may improve clinical responses, in a paradigm of precision medicine.

\section{Conclusions}

This narrative review summarizes the network-based strategies for network discovery and disease outcome prediction and the main findings when applied to GBM studies, along with the software developed and open challenges and future research opportunities. The role of network discovery has long been investigated in biological data, continuously challenged by the fast-growing technological advances. In the particular case of cancer genomics, advanced network-based algorithmic and computational tools are required to translate the vast amounts of high-dimensional and heterogeneous data into molecularlyinformed clinical decisions. Trends in network discovery show a paradigm shift from association to causal discovery, with the premise that causal relationships disclose the 
direction of the association, therefore more meaningful for targeted interventions. While the development of causal inference methods rapidly evolves across several scientific domains, its application to GBM has been seldom investigated. Future GBM network-based studies might encompass a deeper focus of the causal nature of the biological mechanisms behind GBM, further contributing to our scientific understanding of this deadly disease and potentially improving clinical practice.

Author Contributions: M.B.L. and B.M.C. conceptualized the survey; M.B.L., E.P.M., S.V., and B.M.C. wrote the manuscript. All authors read and agreed to the published version of the manuscript.

Funding: This work was partially supported by national funds through Fundação para a Ciência e a Tecnologia (FCT) with references CEECINST/00102/2018, CEECIND/00072/2018 and PD/BDE/143154/2019, UIDB/04516/2020, UIDB/00297/2020, UIDB/50021/2020, UIDB/50022/2020, UIDB/50026/2020, UIDP/50026/2020, NORTE-01-0145-FEDER-000013, and NORTE-01-0145-FEDER000023 and projects PTDC/CCI-BIO/4180/2020 and DSAIPA/DS/0026/2019. This project has received funding from the European Union's Horizon 2020 research and innovation program under Grant Agreement No. 951970 (OLISSIPO project).

Conflicts of Interest: The authors declare no conflict of interest.

\begin{tabular}{ll} 
Abbreviations \\
Banjo & Bayesian network inference with Java objects \\
BN & Bayesian network \\
CE & Community extraction \\
CLR & Context-likelihood-relatedness \\
CNA & Copy number aberration \\
CSPRV & Cancer subtype prediction using $R_{2}$ \\
DAG & Directed acyclic graph \\
DEG & Differential expressed gene \\
DiME & Disease module extraction \\
DINGO & Differential network analysis in genomics \\
EMT & Epithelial-to-mesenchymal transition \\
EPoC & Endogenous perturbation analysis of cancer \\
GBM & Glioblastoma multiforme \\
GBM-BioDP & Glioblastoma Bio Discovery Portal \\
GEO & Gene Expression Omnibus \\
GMM & Gaussian mixture model \\
GO & Gene Ontology \\
GWAS & Genome-wide association study \\
HGG & High-grade glioma \\
IAMB & Incremental associated Markov blanket \\
IDA & Intervention calculus when the DAG is absent \\
iDINGO & Integrative differential network analysis in genomics \\
InTRINSiC & Integrative Modeling of Transcription Regulatory Interactions for \\
KEGG & Systematic Inference of Susceptibility in Cancer \\
KINC & Kyoto Encyclopedia of Genes and Genomes \\
LGG & Knowledge Independent Network Construction \\
TCGA & Low-grade glioma \\
CCLE & The Cancer Genome Atlas \\
CGGA & Cancer Cell Line Encyclopedia \\
EN & Chinese Glioma Genome Atlas \\
lasso & Elastic net \\
lncRNA & Least absolute shrinkage selection operator \\
MI & Long non-coding RNA \\
MSLCRN & Mutual information \\
NGS & Module-specific lncRNA-mRNA causal regulatory networks \\
& Next-generation sequencing \\
\hline
\end{tabular}




$\begin{array}{ll}\text { PDX } & \text { Patient-derived xenograft } \\ \text { RNA-seq } & \text { RNA sequencing } \\ \text { scRNA-seq } & \text { Single-cell RNA sequencing } \\ \text { SNF } & \text { Similarity Network Fusion } \\ \text { SNP } & \text { Single-nucleotide polymorphism } \\ \text { SYGNAL } & \text { Systems Genetics Network Analysis } \\ \text { TAM } & \text { Tumor-associated macrophage } \\ \text { TCI } & \text { Tumor-specific causal inference } \\ \text { TF } & \text { Transcriptional factor } \\ \text { TRN } & \text { Transcriptional regulatory network } \\ \text { twiner } & \text { Twin networks recovery } \\ \text { WGCNA } & \text { Weighted gene coexpression network analysis } \\ \text { WSNF } & \text { Weighted similarity network fusion }\end{array}$

\section{References}

1. Verhaak, R.; Hoadley, K.; Purdom, E.; Wang, V.; Qi, Y.; Wilkerson, M.; Miller, C.; Ding, L.; Golub, T.; Cancer Genome Atlas Research Network; et al. Integrated genomic analysis identifies clinically relevant subtypes of glioblastoma characterized by abnormalities in PDGFRA, IDH1, EGFR, and NF1. Cancer Cell 2010, 17, 98-110. [CrossRef] [PubMed]

2. Dagogo-Jack, I.; Shaw, A. Tumour heterogeneity and resistance to cancer therapies. Nat. Rev. Clin. Oncol. 2018, 15, 81-94. [CrossRef]

3. Gerlinger, M.; Rowan, A.; Horswell, S. Intratumor Heterog. Branched Evol. Reveal. Multiregion Seq. N. Engl. J. Med. 2012, $367,976$.

4. Cohen, R.; Havlin, S. Complex Networks: Structure, Robustness and Function; Cambridge University Press: Cambridge, UK, 2010.

5. Inda, M.; Bonavia, R.; Seoane, J. Glioblastoma multiforme: A look inside its heterogeneous nature. Cancers 2014, 6, 226-239. [CrossRef] [PubMed]

6. Sottoriva, A.; Spiteri, I.; Piccirillo, S.; Touloumis, A.; Collins, V.; Marioni, J.; Curtis, C.; Watts, C.; Tavaré, S. Intratumor heterogeneity in human gliobastoma reflects cancer evolutionary dynamics. Proc. Natl. Acad. Sci. USA 2013, 110, $4009-4014$. [CrossRef]

7. Thakkar, J.; Dolecek, T.; Horbinski, C.; Ostrom, Q.; Lightner, D.; Barnholtz-Sloan, S.; Villano, J. Epidemiologic and molecular prognostic review of glioblastoma. Cancer Epidemiol. Biomarkers Prev. 2014, 23, 1985-1996. [CrossRef] [PubMed]

8. Louis, D.; Perry, A.; Reifenberger, G.; von Deimling, A.; Figarella-Branger, D.; Cavenee, W.; Ohgaki, H.; Wiestler, O.; Kleihues, P.; Ellison, D. The 2016 world health organization classification of tumors of the central nervous system: A summary. Acta Neuropathol. 2016, 131, 803-820. [CrossRef] [PubMed]

9. Stupp, R.; Mason, W.; van den Bent, M.; Weller, M.; Fisher, B.; Taphoorn, M.; Belanger, K.; Brandes, A.; Marosi, C.; Bogdahn, U.; et al. Radiotherapy plus concomitant and adjuvant temozolomide for glioblastoma. N. Engl. J. Med. 2005, 352, 987-996. [CrossRef] [PubMed]

10. Patel, A.; Tirosh, I.; Trombetta, J.; Shalek, A.; Gillespie, S.; Wakimoto, H.; Cahill, D.; Nahed, B.; Curry, W.; Martuza, R.; et al. Single-cell RNA-seq highlights intratumoral heterogeneity in primary glioblastoma. Science 2014, 344, 1396-1401. [CrossRef]

11. Wang, Q.; Hu, B.; Hu, X.; Kim, H.; Squatrito, M.; Scarpace, L.; Verhaak, R.G. Tumor evolution of glioma-intrinsic gene expression subtypes associates with immunological changes in the microenvironment. Cancer Cell 2017, 32, 42-56. [CrossRef]

12. Gill, B.J.; Pisapiab, D.J.; Malone, H.R.; Goldstein, H.; Lei, L.; Sonabend, A.; Yun, J.; Samanamud, J.; Sims, J.S.; Banu, M.; et al. MRI-localized biopsies reveal subtype-specific differences in molecular and cellular composition at the margins of glioblastoma. Proc. Natl. Acad. Sci. USA 2014, 111, 1250-1255. [CrossRef] [PubMed]

13. Hegi, M.E.; Diserens, A.C.; Gorlia, T.; Hamou, M.F.; de Tribolet, N.; Weller, M.; Kros, J.M.; Hainfellner, J.A.; Mason, W.; Mariani, L.; et al. MGMT Gene Silenc. Benefit Temozolomide Glioblastoma. N. Engl. J. Med. 2005, 352, 997-1003. [CrossRef] [PubMed]

14. Ha, M.; Baladandayuthapani, V.; Do, K.A. DINGO: Differential network analysis in genomics. Bioinformatics 2015, 31, 3413-3420. [CrossRef]

15. Velpula, K.K.; Bhasin, A.; Asuthkar, S.; Tsung, A.J. Combined Targeting of PDK1 and EGFR Triggers Regression of Glioblastoma by Reversing the Warburg Effect. Cancer Res. 2013, 73, 7277-7289. [CrossRef] [PubMed]

16. Meir, E.G.V.; Hadjipanayis, C.G.; Norden, A.D.; Shu, H.K.; Wen, P.Y.; Olson, J.J. Exciting new advances in neuro-oncology: The avenue to a cure for malignant glioma. CA Cancer J. Clin. 2010, 60, 166-193. [CrossRef]

17. The Cancer Genome Atlas Res. Network. Comprehensive genomic characterization defines human glioblastoma genes and core pathways. Nature 2008, 455, 1061-1068. [CrossRef]

18. Mellinghof, I.K.; Wang, M.Y.; Vivanco, I.; Haas-Kogan, D.A.; Zhu, S.; Dia, E.Q.; Lu, K.V.; Yoshimoto, K.; Huang, J.H.; Chute, D.J.; et al. Molecular Determinants of the Response of Glioblastomas to EGFR Kinase Inhibitors. N. Engl. J. Med. 2005, 353, 2012-2024. [CrossRef]

19. Wen, P.Y.; Lee, E.Q.; Reardon, D.A.; Ligon, K.L.; Yung, W.A. Current clinical development of PI3K pathway inhibitors in glioblastoma. Neuro-Oncology 2012, 14, 819-829. [CrossRef] 
20. Masui, K.; Tanaka, K.; Akhavan, D.; Babic, I.; Gini, B.; Matsutani, T.; Iwanami, A.; Liu, F.; Villa, G.R.; Gu, Y.; et al. mTOR Complex 2 Controls Glycolytic Metabolism in Glioblastoma through FoxO Acetylation and Upregulation of c-Myc. Cell Metab. 2013, 18, 726-739. [CrossRef]

21. Tateishi, K.; Iafrate, A.J.; Ho, Q.; Curry, W.T.; Batchelor, T.T.; Flaherty, K.T.; Onozato, M.L.; Lelic, N.; Sundaram, S.; Cahill, D.P.; et al. Myc-driven glycolysis is a therapeutic target in glioblastoma. Clin. Cancer Res. 2016, 22, 4452-4465. [CrossRef]

22. Ning, J.F.; Stanciu, M.; Humphrey, M.R.; Gorham, J.; Wakimoto, H.; Nishihara, R.; Lees, J.; Zou, L.; Martuza, R.L.; Wakimoto, H.; et al. Myc targeted CDK18 promotes ATR and homologous recombination to mediate PARP inhibitor resistance in glioblastoma. Nat. Commun. 2019, 10, 2910. [CrossRef] [PubMed]

23. Moncini, S.; Salvi, A.; Zuccotti, P.; Viero, G.; Quattrone, A.; Barlati, S.; Petro, G.D.; Venturin, M.; Riva, P. The Role of miR-103 and miR-107 in Regulation of CDK5R1 Expression and in Cellular Migration. PLoS ONE 2011, 6, e20038. [CrossRef] [PubMed]

24. Tsai, L.H.; Delalle, I., Caviness, V.S., Jr.; Chae, T.; Harlow, E. p35 is a neural-specific regulatory subunit of cyclin-dependent kinase 5. Nature 1994, 371, 419-423. [CrossRef] [PubMed]

25. Catania, A.; Urban, S.; Yan, E.; Hao, C.; Barron, G.; Allalunis-Turner, J. Expression and localization of cyclin- dependent kinase 5 in apoptotic human glioma cells. Neuro-Oncology 2001, 3, 89-98. [CrossRef] [PubMed]

26. Liu, R.; Tian, B.; Gearing, M.; Hunter, S.; Ye, K.; Mao, Z. Cdk5-mediated regulation of the PIKE-A-Akt pathway and glioblastoma cell invasion. Proc. Natl. Acad. Sci. USA 2008, 105, 7570-7575. [CrossRef]

27. Yushan, R.; Wenjie, C.; Suning, H.; Yiwu, D.; Tengfei, Z.; Madushi, W.M.; Feifei, L.; Changwen, Z.; Xin, W.; Roodrajeetsing, G.; et al. Insights into the clinical value of cyclin-dependent kinase 5 in glioma: A retrospective study. World J. Surg. Oncol. 2015, 13. [CrossRef]

28. Dorand, R.D.; Nthale, J.; Myers, J.T.; Barkauskas, D.S.; Avril, S.; Chirieleison, S.M.; Pareek, T.K.; Abbott, D.W.; Stearns, D.S.; Letterio, J.J.; et al. Cdk5 disruption attenuates tumor PD-L1 expression and promotes antitumor immunity. Science 2016, 353, 399-403. [CrossRef]

29. Mukherjee, S.; Tucker-Burden, C.; Kaissi, E.; Newsam, A.; Duggireddy, H.; Chau, M.; Zhang, C.; Diwedi, B.; Rupji, M.; Seby, S.; et al. CDK5 Inhibition Resolves PKA/cAMP-Independent Activation of CREB1 Signaling in Glioma Stem Cells. Cell Rep. 2018, 23, 1651-1664. [CrossRef]

30. Sang, Y.; Li, Y.; Zhang, Y.; Alvarez, A.A.; Yu, B.; Zhang, W.; Hu, B.; Cheng, S.Y.; Feng, H. CDK5-dependent phosphorylation and nuclear translocation of TRIM59 promotes macroH2A1 ubiquitination and tumorigenicity. Nat. Commun. 2019, 10, 4013. [CrossRef]

31. Madhavan, S.; Zenklusen, J.; Kotliarov, Y.; Sahni, H.; Fine, H.; Buetow, K. Rembrandt: Helping personalized medicine become a reality through integrative translational research. Mol. Cancer Res. 2009, 7, 157-167. [CrossRef]

32. Edgar, R.; Domrachev, M.; Lash, A. Gene Expression Omnibus: NCBI gene expression and hybridization array data repository. Nucleic Acids Res. 2002, 30, 207-210. [CrossRef]

33. Wheeler, D.L.; Barrett, T.; Benson, D.A.; Bryant, S.H.; Canese, K.; Chetvernin, V.; Yaschenko, E. Database resources of the national center for biotechnology information. Nucleic Acids Res. 2007, 36, D13-D21. [CrossRef]

34. Celiku, O.; Johnson, S.; Zhao, S.; Camphausen, K.; Shankavaram, U. Visualizing molecular profiles of glioblastoma with GBM-BioDP. PLoS ONE 2014, 9, e101239. [CrossRef]

35. Barretina, J.; Caponigro, G.; Stransky, N.; Venkatesan, K.; Margolin, A.A.; Kim, S.; Garraway, L.A. The Cancer Cell Line Encyclopedia enables predictive modelling of anticancer drug sensitivity. Nature 2012, 483, 603-607. [CrossRef]

36. Zhao, Z.; Zhang, K.; Wang, Q.; Li, G.; Zeng, F.; Zhang, Y.; Wu, F.; Chai, R.; Wang, Z.; Zhang, C.; et al. Chinese Glioma Genome Atlas (CGGA): A Comprehensive Resource with Functional Genomic Data for Chinese Glioma Paties. bioRxiv 2020. [CrossRef]

37. Langfelder, P.; Horvath, S. WGCNA: An R package for weighted correlation network analysis. BMC Bioinform. 2008, 9, 1-13.

38. Liu, Y.; Tennant, D.; Zhu, Z.; Heath, J.; Yao, X.; He, S. DiME: A Scalable Disease Module Identification Algorithm with Application to Glioma Progression. PLoS ONE 2014, 9, e86693. [CrossRef] [PubMed]

39. Ficklin, S.; Dunwoodie, L.; Poehlman, W.; Watson, C.; Roche, K.; Feltus, F. Discovering Condition-Specific Gene Co-Expression Patterns Using Gaussian Mixture Models: A Cancer Case Study. Sci. Rep. 2017, 7, 8617. [CrossRef] [PubMed]

40. Xu, T.; Le, T.; Liu, L.; Wang, R.; Sun, B.; Li, J. Identifying Cancer Subtypes from miRNA-TFmRNA Regulatory Networks and Expression Data. PLOS ONE 2016, 11, e0152792.

41. Guo, Y.; Qi, Y.; Li, Z.; Shang, X. Improvement of cancer subtype prediction by incorporating transcriptome expression data and heterogeneous biological networks. BMC Med. Gnomics 2018, 11, 119. [CrossRef] [PubMed]

42. Veríssimo, A.; Vinga, S.; Carrasquinha, E.; Lopes, M. Network Centrality Metrics for Elastic-Net Regularized Models. Bioconductor R Package Version 3.11 2018. Available online: https:/ / www.bioconductor.org/packages/release/bioc/html/glmSparseNet. html (accessed on 1 February 2021).

43. Verissimo, A.; Carrasquinha, E.; Lopes, M.; Oliveira, A.; Sagot, M.F.; Vinga, S. Sparse network-based regularization for the analysis of patientomics high-dimensional survival data. bioRxiv 2018. [CrossRef]

44. Le, T.; Hoang, T.; Li, J.; Liu, L.; Hu, S. ParallelPC: An R package for efficient constraint based causal exploration. arXiv 2015, arXiv:1510.03042v1.

45. Zhang, J.; Le, T.; Liu, L.; Li, J. Inferring and analyzing module-specific lncRNA-mRNA causal regulatory networks in human cancer. Briefings Bioinform. 2018, 20, 1403-1419. [CrossRef] 
46. Faith, J.; Hayete, B.; Thaden, J.; Mogno, I.; Wierzbowski, J.; Cottarel, G.; Kasif, S.; Collins, J.; Gardner, T. Large-scale mapping and validation of Escherichia coli transcriptional regulation from a compendium of expression profiles. PLoS Biol. 2007, 5, e8. [CrossRef] [PubMed]

47. Liu, Y.; Shi, N.; Regev, A.; He, S.; Hemann, M. Integrated regulatory models for inference of subtype-specific susceptibilities in glioblastoma. Mol. Syst. Biol. 2020, 16, e9506. [CrossRef]

48. Scutari, M. Learning Bayesian Networks with the bnlearn R Package. J. Stat. Softw. 2010, 35, 1-20. [CrossRef]

49. Hartemink, A. Banjo: Bayesian Network Inference with Java Objects; Version 2.2.0; Duke University: Durham, NC, USA, 2005.

50. Horvath, S.; Zhang, B.; Carlson, M.; Lu, K.; Zhu, S.; Felciano, R.; Laurance, M.; Zhao, W.; Qi, S.; Chen, Z.; et al. Analysis of oncogenic signaling networks in glioblastoma identifies ASPM as a molecular target. Proc. Natl. Acad. Sci. USA 2006, 103, 17402-17407. [CrossRef] [PubMed]

51. Zhang, B.; Horvath, S. A General Framework for Weighted Gene Co-Expression Network Analysis. Stat. Appl. Genet. Mol. Biol. 2005, 4, 17. [CrossRef] [PubMed]

52. Hagemann, C.; Anacker, J.; Gerngras, S.; Kühnel, S.; Said, H.M.; Patel, R.; Kämmerer, U.; Vordermark, D.; Roosen, K.; Vince, G.H. Expression analysis of the autosomal recessive primary microcephaly genes MCPH1 (microcephalin) and MCPH5 (ASPM, abnormal spindle-like, microcephaly associated) in human malignant gliomas. Oncol. Rep. 2008, 20, 301-308. [CrossRef]

53. Bikeye, S.N.N.; Colin, C.; Marie, Y.; Vampouille, R.; Ravassard, P.; Rousseau, A.; Boisselier, B.; Idbaih, A.; Calvo, C.F.; Leuraud, P.; et al. ASPM-associated stem cell proliferation is involved in malignant progression of gliomas and constitutes an attractive therapeutic target. Cancer Cell Int. 2010, 10, 1-9.

54. Visnyei, K.; Onodera, H.; Damoiseaux, R.; Saigusa, K.; Petrosyan, S.; Vries, D.D.; Ferrari, D.; Saxe, J.; Panosyan, E.H.; MastermanSmith, M.; et al. A molecular screening approach to identify and characterize inhibitors of glioblastoma stem cells. Mol. Cancer Ther. 2011, 10, 1818-1828. [CrossRef] [PubMed]

55. Chen, X.; Huang, L.; Yang, Y.; Chen, S.; Sun, J.; Ma, C.; Xie, J.; Song, Y.; Yang, J. ASPM promotes glioblastoma growth by regulating G1 restriction point progression and Wnt- $\beta$-catenin signaling. Aging 2020, 12, 224-241. [CrossRef]

56. Tso, C.L.; Freije, W.A.; Day, A.; Chen, Z.; Merriman, B.; Perlina, A.; Lee, Y.; Dia, E.Q.; Yoshimoto, K.; Mischel, P.S.; et al. Distinct transcription profiles of primary and secondary glioblastoma subgroups. Cancer Res. 2006, 66, 159-167. [CrossRef]

57. Marie, S.K.N.; Okamoto, O.K.; Uno, M.; Hasegawa, A.P.G.; Oba-Shinjo, S.M.; Cohen, T.; Camargo, A.A.; Kosoy, A.; Carlotti, C.G., Jr.; Toledo, S.; et al. Maternal embryonic leucine zipper kinase transcript abundance correlates with malignancy grade in human astrocytomas. Int. J. Cancer 2008, 122, 807-815. [CrossRef] [PubMed]

58. Rahane, C.S.; Kutzner, A.; Heese, K. A cancer tissue-specific FAM72 expression profile defines a novel glioblastoma multiform (GBM) gene-mutation signature. J. Neuro-Oncol. 2019, 144, 57-70. [CrossRef]

59. Zou, Y.F.; Meng, L.B.; He, Z.K.; Hu, C.H.; Shan, M.J.; Wang, D.Y.; Yu, X. Screening and authentication of molecular markers in malignant glioblastoma based on gene expression profiles. Oncol. Lett. 2019, 18, 4593-4604. [CrossRef] [PubMed]

60. Zhao, L.; Zhang, J.; Liu, Z.; Zhao, P. Identification of biomarkers for the transition from low-grade glioma to secondary glioblastoma by an integrated bioinformatic analysis. Am. J. Transl. Res. 2020, 12, 1222-1238. [PubMed]

61. Chen, T.; Liu, Y.; Chen, L.; Luo, J.; Zhang, C.; Shen, X. Identification of the potential biomarkers in patients with glioma: A weighted gene co-expression network analysis. Carcinogenesis 2020, 41, 743-750. [CrossRef]

62. Tang, X.; Xu, P.; Wang, B.; Luo, J.; Fu, R.; Huang, K.; Dai, L.; Lu, J.; Cao, G.; Peng, H.; et al. Identification of a Specific Gene Module for Predicting Prognosis in Glioblastoma Patients. Front. Oncol. 2019, 9, 812. [CrossRef] [PubMed]

63. Li, M.; Long, S.; Hu, J.; Wang, Z.; Geng, C.; Ou, S. Systematic identification of lncRNA-based prognostic biomarkers for glioblastoma. Aging 2019, 11, 9405-9423. [CrossRef]

64. Liang, R.; Zhi, Y.; Zheng, G.; Zhang, B.; Zhu, H.; Wang, M. Analysis of long non-coding RNAs in glioblastoma for prognosis prediction using weighted gene co-expression network analysis, Cox regression, and L1-LASSO penalization. OncoTargets Ther. 2019, 12, 157-168. [CrossRef]

65. Xu, P.; Yang, J.; Liu, J.; Yang, X.; Liao, J.; Yuan, F.; Xu, Y.; Chen, B.L.Q. Identification of glioblastoma gene prognosis modules based on weighted gene co-expression network analysis. BMC Med. Genom. 2018, 11, 96. [CrossRef]

66. Chen, X.; Pan, C.; Xu, C.; Sun, Y.; Geng, Y.; Kong, L.; Xiao, X.; Zhao, Z.; Zhou, W.; Huang, L.; et al. Identification of survival-associated key genes and long non-coding RNAs in glioblastoma multiforme by weighted gene co-expression network analysis. Int. J. Mol. Med. 2018, 43, 1709-1722. [CrossRef] [PubMed]

67. Upton, A.; Arvanitis, T. Using Evolutional Properties of Gene Networks in Understanding Survival Prognosis of Glioblastoma. IEEE J. Biomed. Health Inform. 2014, 18, 810-816. [CrossRef] [PubMed]

68. Ivliev, A.; 't Hoen, P.; Sergeeva, M. Coexpression Network Analysis Identifies Transcriptional Modules Related to Proastrocytic Differentiation and Sprouty Signaling in Glioma. Cancer Res. 2010, 70, 10060-10070. [CrossRef]

69. Zhao, Y.; Levina, E.; Zhu, J. Community extraction for social networks. Proc. Natl. Acad. Sci. USA 2011, 108, 7321-7326. [CrossRef]

70. Yu, H.; Li, Z.; Wang, M. Expression and prognostic role of E2F transcription factors in high-grade glioma. CNS Neurosci. Ther. 2020, 26, 741-743. [CrossRef] [PubMed]

71. Yu, X.; Jiang, Y.; Wei, W.; Cong, P.; Ding, Y.; Xiang, L.; Wu, K. Androgen receptor signaling regulates growth of glioblastoma multiforme in men. Tumor Biol. 2015, 36, 967-972. [CrossRef] [PubMed]

72. Hu, C.; Fang, D.; Xu, H.; Wang, Q.; Xia, H. The androgen receptor expression and association with patient's survival in different cancers. Genomics 2020, 112, 1926-1940. [CrossRef] [PubMed] 
73. Werner, C.K.; Nna, U.J.; Sun, H.; Wilder-Romans, K.; Dresser, J.; Kothari, A.U.; Zhou, W.; Yao, Y.; Rao, A.; Stallard, S.; et al. Expression of the Androgen Receptor Governs Radiation Resistance in a Subset of Glioblastomas Vulnerable to Antiandrogen Therapy. Mol. Cancer Ther. 2020, 19, 2163-2174. [CrossRef] [PubMed]

74. Chang, K.F.; Huang, X.F.; Chang, J.T.; Huang, Y.C.; Weng, J.C.; Tsai, N.M. Cedrol suppresses glioblastoma progression by triggering DNA damage and blocking nuclear translocation of the androgen receptor. Cancer Lett. 2020, 495, 180-190. [CrossRef]

75. Orozco, M.; Valdez, R.; Ramos, L.; Cabeza, M.; Segovia, J.; Romano, M. Dutasteride combined with androgen receptor antagonists inhibit glioblastoma U87 cell metabolism, proliferation, and invasion capacity: Androgen regulation. Steroids 2020, 164, 108733. [CrossRef]

76. Chen, T.C.; Chuang, J.Y.; Ko, C.Y.; Kao, T.J.; Yang, P.Y.; Yu, C.H.; Liu, M.S.; Hu, S.L.; Tsai, Y.T.; Chan, H.; et al. AR ubiquitination induced by the curcumin analog suppresses growth of temozolomide-resistant glioblastoma through disrupting GPX4-Mediated redox homeostasis. Redox Biol. 2020, 30, 101413. [CrossRef]

77. Nakada, M.; Yamashita, J.; Okada, Y.; Sato, H. Ets-1 positively regulates expression of Urokinase-type Plasminogen Activator (uPA) and invasiveness of astrocytic tumors. J. Neuropathol. Exp. Neurol. 1999, 58, 329-334. [CrossRef] [PubMed]

78. Valter, M.M.; Hügel, A.; Huang, H.J.; Cavenee, W.K.; Wiestler, O.D.; Pietsch, T.; Wernert, N. Expression of the Ets-1 transcription factor in human astrocytomas is associated with fms-like tyrosine kinase-1 (Flt-1)/vascular endothelial growth factor receptor-1 synthesis and neoangiogenesis. Cancer Res. 1999, 59, 5608-5614.

79. Shukla, A.A.; Jain, M.; Chauhan, S.S. Ets-1/Elk-1 is a critical mediator of dipeptidyl-peptidase III transcription in human glioblastoma cells. FEBS J. 2010, 277, 1861-1875. [CrossRef]

80. Li, Y.; Zhou, Q.L.; Sun, W.; Chandrasekharan, P.; Cheng, H.S.; Ying, Z.; Lakshmanan, M.; Raju, A.; Tenen, D.G.; Cheng, S.Y.; et al. Non-canonical NF-kB signalling and ETS1/2 cooperatively drive C250T mutant TERT promoter activation. Nat. Cell Biol. 2015, 17, 1327-1338. [CrossRef] [PubMed]

81. Bell, R.J.; Rube, H.T.; Xavier-Magalhães, A.; Costa, B.M.; Mancini, A.; Song, J.S.; Costello, J.F. Understanding TERT Promoter Mutations: A Common Path to Immortality. Mol. Cancer Res. 2016, 14, 315-323. [CrossRef] [PubMed]

82. Mancini, A.; Xavier-Magalhães, A.; Woods, W.S.; Nguyen, K.T.; Amen, A.M.; Hayes, J.L.; Fellmann, C.; Gapinske, M.; McKinney, A.M.; Hong, C.; et al. Disruption of the $\beta 1 \mathrm{~L}$ Isoform of GABP Reverses Glioblastoma Replicative Immortality in a TERT Promoter Mutation-Dependent Manner. Cancer Cell 2018, 34, 513-528. [CrossRef]

83. Dunwoodie, L.; Poehlman, W.; Ficklin, S.; Feltus, F. Discovery and validation of a glioblastoma co-expressed gene module. Oncotarget 2018, 9, 10995-11008. [CrossRef]

84. Wang, X.; Ning, W.; Qiu, Z.; Li, S.; Zhang, H.; Yu, C. Tumor-associated macrophages based signaling pathway analysis and hub genes identification in glioma. Medicine 2020, 99, e23840. [CrossRef] [PubMed]

85. Class, C.; Ha, M.; Baladandayuthapani, V.; Do, K.A. iDINGO-Integrative differential network analysis in genomics with Shiny application. Bioinformatics 2015, 34, 1243-1245. [CrossRef]

86. Jörnsten, R.; Abenius, T.; Kling, T.; Schmidt, L.; Johansson, E.; Nordling, T.; Nordlander, B.; Sander, C.; Gennemark, P.; Funa, K.; et al. Network modeling of the transcriptional effects of copy number aberrations in glioblastoma. Mol. Syst. Biol. 2011, 7, 486. [CrossRef]

87. Hansen, L.J.; Sun, R.; Yang, R.; Singh, S.X.; Chen, L.H.; Pirozzi, C.J.; Moure, C.J.; Hemphill, C.; Carpenter, A.B.; Healy, P.; et al. MTAP loss promotes stemness in glioblastoma and confers unique susceptibility to purine starvation. Cancer Res. 2019, 79, 3383-3394. [CrossRef]

88. De Menezes, W.; Silva, V.A.O.; Gomes, I.N.F.; Rosa, M.N.; Spina, M.L.C.; Carloni, A.C.; Alves, A.L.V.; Melendez, M.; Almeida, G.C.; da Silva, L.S.; et al. Loss of 5'-Methylthioadenosine Phosphorylase (MTAP) is Frequent in High-Grade Gliomas; Nevertheless, it is Not Associated with Higher Tumor Aggressiveness. Cells 2020, 9, 492. [CrossRef]

89. Liu, B.; Liu, J.; Liao, Y.; Jin, C.; Zhang, Z.; Zhao, J.; Liu, K.; Huang, H.; Cao, H.; Cheng, Q. Identification of SEC61G as a novel prognostic marker for predicting survival and response to therapies in patients with glioblastoma. Med. Sci. Monit. 2019, 25, 3624-3635. [CrossRef]

90. Korkolopoulou, P.; Levidou, G.; El-Habr, E.A.; Adamopoulos, C.; Fragkou, P.; Boviatsis, E.; Themistocleous, M.S.; Petraki, K.; Vrettakos, G.; Sakalidou, M.; et al. Sox11 expression in astrocytic gliomas: Correlation with nestin/c-Met/IDH1-R132H expression phenotypes, p-Stat-3 and survival. Br. J. Cancer 2013, 108, 2142-2152. [CrossRef]

91. Camacho-Urkaray, E.; Santos-Juanes, J.; Gutiérrez-Corres, F.B.; García, B.; Quirós, L.M.; Guerra-Merino, I.; Aguirre, J.J.; FernándezVega, I. Establishing cut-off points with clinical relevance for bcl-2, cyclin D1, p16, p21, p27, p53, Sox11 and WT1 expression in glioblastoma-A short report. Cell. Oncol. 2018, 41, 213-221. [CrossRef] [PubMed]

92. Zhang, W.; Chen, H.; Lv, S.; Yang, H. High CD133 Expression Is Associated with Worse Prognosis in Patients with Glioblastoma. Mol. Neurobiol. 2016, 53, 2354-2360. [CrossRef] [PubMed]

93. Genovese, G.; Ergun, A.; Shukla, S.; Campos, B.; Hanna, J.; Ghosh, P.; Quayle, S.; Rai, K.; Colla, S.; Ying, H.; et al. microRNA regulatory network inference identifies miR-34a as a novel regulator of TGF-beta signaling in glioblastoma. Cancer Discov. 2012, 2, 736-749. [CrossRef] [PubMed]

94. Silber, J.; Jacobsen, A.; Ozawa, T.; Harinath, G.; Pedraza, A.; Sander, C.; Holland, E.; Huse, J. miR-34a Repression in Proneural Malignant Gliomas Upregulates Expression of Its Target PDGFRA and Promotes Tumorigenesis. PLoS ONE 2012, 7, e33844. [CrossRef] 
95. Xiong, Y.; Wang, Q. STC1 regulates glioblastoma migration and invasion via the TGF- $\beta$ /SMAD4 signaling pathway. Mol. Med. Rep. 2019, 20, 3055-3064. [CrossRef] [PubMed]

96. Wang, B.; Mezlini, A.; Demir, F.; Fiume, M.; Tu, Z.; Brudno, M.; Haibe-Kains, B.; Goldenberg, A. Similarity network fusion for aggregating data types on a genomic scale. Nat. Methods 2014, 11, 333. [CrossRef]

97. Smilde, A.; Kiers, H.; Bijlsma, S.; Rubingh, C.; van Erk, M. Matrix correlations for high-dimensional data: The modified RV-coefficient. Bioinformatics 2009, 25, 401-405. [CrossRef] [PubMed]

98. Vinga, S. Structured sparsity regularization for analyzing high-dimensional omics data. Briefings Bioinform. 2021, 22, 77-87. [CrossRef] [PubMed]

99. Tibshirani, R. Regression shrinkage and selection via the lasso. J. R. Stat. Soc. Ser. B 1996, 58, 267-288. [CrossRef]

100. Zou, H.; Hastie, T. Regularization and variable selection via the elastic net. J. R. Stat. Soc. Ser. B 2005, 67, 301-320. [CrossRef]

101. Tibshirani, R.; Saunders, M.; Rosset, S.; Zhu, J.; Knight, K. Sparsity and smoothness via the fused lasso. J. R. Stat. Soc. Ser. B 2005, 67, 91-108. [CrossRef]

102. Zou, H.; Hastie, T. The adaptive lasso and its oracle properties. J. Am. Stat. Assoc. 2006, 101, 1418-1429. [CrossRef]

103. Yuan, M.; Lin, Y. Model selection and estimation in regression with grouped variables. J. R. Stat. Soc. Ser. B $2006,68,49-67$. [CrossRef]

104. Li, C.; Li, H. Network-constrained regularization and variable selection for analysis of genomic data. Bioinformatics 2008, 24, 1175-1182. [CrossRef] [PubMed]

105. Paradisis, S.; Ruvkun, G. Caenorhabditis elegans Akt/PKB transduces insulin receptor-like signals from AGE-1 PI3 kinase to the DAF-16 transcription factor. Genes Dev. 1998, 12, 2488-2498. [CrossRef] [PubMed]

106. Brunet, A.; Bonni, A.; Zigmond, M.J.; Lin, M.Z.; Juo, P.; Hu, L.S.; Anderson, M.J.; Arden, K.C.; Blenis, J.; Greenberg, M.E. Akt promotes cell survival by phosphorylating and inhibiting a forkhead transcription factor. Cell 1999, 96, 857-868. [CrossRef]

107. Li, J.; Yen, C.; Liaw, D.; Podsypanina, K.; Bose, S.; Wang, S.I.; Puc, J.; Miliaresis, C.; Rodgers, L.; McCombie, R.; et al. PTEN, A Putative Protein Tyrosine Phosphatase Gene Mutated Hum. Brain, Breast, Prostate Cancer. Science 1997, $275,1943-1947$. [CrossRef]

108. Carracedo, A.; Pandolfi, P. The PTEN-PI3K pathway: Of feedbacks and cross-talks. Oncogene 2008, 27, 5527-5541. [CrossRef]

109. Swartling, F.; Ferletta, M.; Kastemar, M.; Weiss, W.; Westermark, B. Cyclic GMP-dependent protein kinase II inhibits cell proliferation, Sox9 expression and Akt phosphorylation in human glioma cell lines. Oncogene 2009, 28, 3121-3131. [CrossRef]

110. Dhanasekaran, D.; Kashef, K.; Lee, C.; Xu, H.; Reddy, E. Scaffold proteins of MAP-kinase modules. Oncogene 2007, 26, 3185-3202. [CrossRef]

111. Demuth, T.; Reavie, L.B.; Rennert, J.L.; Nakada, M.; Nakada, S.; Hoelzinger, D.B.; Beaudry, C.E.; Henrichs, A.N.; Anderson, E.M.; Berens, M.E. MAP-ing glioma invasion: Mitogen-activated protein kinase kinase 3 and p38 drive glioma invasion and progression and predict patient survival. Mol. Cancer Ther. 2007, 6, 1212-1222. [CrossRef]

112. Wagner, E.F.; Nebreda, Á.R. Signal integration by JNK and p38 MAPK pathways in cancer development. Nat. Rev. Cancer 2009, 9, 537-549. [CrossRef] [PubMed]

113. Uht, R.; Amos, S.; Martin, P.; Riggan, A.; Hussaini, I. The protein kinase $\mathrm{C} \eta$ - isoform induces proliferation in glioblastoma cell lines through an ERK/Elk-1 pathway. Oncogene 2007, 26, 2885-2893. [CrossRef]

114. Zhang, N.; Wei, P.; Gong, A.; Chiu, W.T.; Lee, H.T.; Colman, H.; Huang, H.; Xue, J.; Liu, M.; Wang, Y.; et al. FoxM1 Promotes $\beta$-Catenin Nuclear Localization and Controls Wnt Target-Gene Expression and Glioma Tumorigenesis. Cancer Cell 2011, 18, 427-442. [CrossRef]

115. Xue, J.; Chen, Y.; Wu, Y.; Wang, Z.; Zhou, A.; Zhang, S.; Lin, K.; Aldape, K.; Majumder, S.; Lu, Z.; et al. Tumour suppressor TRIM33 targets nuclear $\beta$-catenin degradation. Nat. Commun. 2015, 6, 6156. [CrossRef] [PubMed]

116. Fecci, P.E.; Ochiai, H.; Mitchell, D.A.; Grossi, P.M.; Sweeney, A.E.; Archer, G.E.; Cummings, T.; Allison, J.P.; Bigner, D.D.; Sampson, J.H. Systemic CTLA-4 blockade ameliorates glioma-induced changes to the CD4 + T cell compartment without affecting regulatory T-cell function. Clin. Cancer Res. 2007, 13, 2158-2167. [CrossRef] [PubMed]

117. Liebner, S.; Fischmann, A.; Rascher, G.; Duffner, F.; Grote, E.H.; Kalbacher, H.; Wolburg, H. Claudin-1 and claudin-5 expression and tight junction morphology are altered in blood vessels of human glioblastoma multiforme. Acta Neuropathol. 2000, 100, 323-331. [CrossRef]

118. Wolburg, H.; Wolburg-Buchholz, K.; Kraus, J.; Rascher-Eggstein, G.; Liebner, S.; Hamm, S.; Duffner, F.; Grote, E.H.; Risau, W.; Engelhardt, B. Localization of claudin-3 in tight junctions of the blood-brain barrier is selectively lost during experimental autoimmune encephalomyelitis and human glioblastoma multiforme. Acta Neuropathol. 2003, 105, 586-592. [CrossRef] [PubMed]

119. Lopes, M.B.; Veríssimo, A.; Carrasquinha, E.; Vinga, S. On the Role of Hub and Orphan Genes in the Diagnosis of Breast Invasive Carcinoma. In Machine Learning, Optimization, and Data Science; Nicosia, G., Pardalos, P., Umeton, R., Giuffrida, G., Sciacca, V., Eds.; Springer International Publishing: Cham, Switzerland, 2019; pp. 631-642.

120. Carrasquinha, E.; Veríssimo, A.; Lopes, M.B.; Vinga, S. Network-Based Variable Selection for Survival Outcomes in Oncological Data. In Bioinformatics and Biomedical Engineering; Rojas, I., Valenzuela, O., Rojas, F., Herrera, L.J., Ortuño, F., Eds.; Springer International Publishing: Cham, Switzerland, 2020; pp. 550-561.

121. Veríssimo, A.; Oliveira, A.; Sagot, M.F.; Vinga, S. DegreeCox-A network-based regularization method for survival analysis. J. R. Stat. Soc. Ser. B 2016, 77, 449. [CrossRef] 
122. Friedman, J.; Hastie, T.; Tibshirani, R. Regularization Paths for Generalized Linear Models via Coordinate Descent. J. Stat. Softw. 2010, 33, 1-22. [CrossRef] [PubMed]

123. Lopes, M.; Vinga, S. Tracking intratumoral heterogeneity in glioblastoma via regularized classification of single-cell RNA-Seq data. BMC Bioinform. 2020, 21, 59. [CrossRef]

124. Lopes, M.; Casimiro, S.; Vinga, S. Twiner: Correlation-based regularization for identifying common cancer gene signatures. BMC Bioinform. 2019, 20, 356. [CrossRef] [PubMed]

125. Peixoto, C.; Martins, M.L.M.; Costa, L.; Vinga, S. TCox: Correlation-Based Regularization Applied to Colorectal Cancer Survival Data. Biomedicines 2020, 8, 488. [CrossRef]

126. Darmanis, S.; Sloan, S.; Croote, D.; Mignardi, M.; Chernikova, S.; Samghababi, P.; Zhang, Y.; Neff, N.; Kowarsky, M.; Caneda, C.; et al. Single-Cell RNA-Seq Analysis of Infiltrating Neoplastic Cells at the Migrating Front of Human Glioblastoma. Cell Rep. 2017, 21, 1399-1410. [CrossRef]

127. Nørøxe, D.; Poulsen, H.; Lasses, U. Hallmarks of glioblastoma: A systematic review. ESMO Open 2016, 1, e000144. [CrossRef] [PubMed]

128. Brennan, C.; Verhaak, R.; McKenna, A.; Campos, B.; Noushmehr, H.; Salama, S.; Zheng, S.; Chakravarty, D.; Sanborn, J.; Berman, S.; et al. The somatic genomic landscape of glioblastoma. Cell 2013, 155, 462-477. [CrossRef]

129. Yang, Y.; Liu, Y.; Yao, X.; Ping, Y.; Jiang, T.; Liu, Q.; Xu, S.; Huang, J.; Mou, H.; Gong, W.; et al. Annexin 1 released by necrotic Human glioblastoma cells stimulates tumor cell growth through the formyl peptide receptor 1. Am. J. Pathol. 2011, 179, 1504-1512. [CrossRef]

130. Svenningsen, A.; Löring, S.; Sørensen, A.; Huynh, H.; Hjæresen, S.; Martin, N.; Moeller, J.; Elkjær, M.; Holmskov, U.; Illes, Z.; et al. Macrophage migration inhibitory factor (MIF) modulates trophic signaling through interaction with serine protease HTRA1. Cell. Mol. Life Sci. 2017, 74, 4561-4572. [CrossRef] [PubMed]

131. Wei, Y.; Vellanki, R.; Coyaud, E.; Ignatchenko, V.; Li, L.; Krieger, J.; Taylor, P.; Tong, J.; Pham, N.A.; Liu, G.; et al. CHCHD2 is coamplified with EGFR in NSCLC and regulates mitochondrial function and cell migration. Mol. Cancer Res. 2015, 13, 1119-1129. [CrossRef] [PubMed]

132. Vogt, N.; Gibaud, A.; Almeida, A.; Ourliac-Garnier, I.; Debatisse, M.; Malfoy, B. Relationships linking amplification level to gene over-expression in gliomas. PLoS ONE 2010, 5, e14249. [CrossRef] [PubMed]

133. Wang, L.; He, S.; Yuan, J.; Mao, X.; Cao, Y.; Zong, J.; Tu, Y.; Zhang, Y. Oncogenic role of SOX9 expression in human malignant glioma. Med. Oncol. 2012, 29, 3484-3490. [CrossRef]

134. Jiang, J.; Zhou, J.; Luo, P.; Gao, H.; Ma, Y.; Chen, Y.S.; Li, L.; Zou, D.; Zhang, Y.; Jing, Z. Prosaposin promotes the proliferation and tumorigenesis in glioma through toll-like receptor 4 (TLR4)-mediated NF- $\kappa$ B signaling pathway. EBioMedicine 2018, 37, 78-90. [CrossRef]

135. Gont, A.; Daneshmand, M.; Woulfe, J.; Lorimer, I. PREX1 integrates G protein-coupled receptor and phosphoinositide 3-kinase signaling to promote glioblastoma invasion. Eur. J. Cancer 2016, 61, S171-S172. [CrossRef]

136. Golan-Gerstl, R.; Cohen, M.; Shilo, A.; Suh, S.S.; Bakàcs, A.; Coppola, L.; Karni, R. Splicing factor hnRNP A2/B1 regulates tumor suppressor gene splicing and is an oncogenic driver in glioblastoma. Cancer Res. 2011, 71, 4464-4472. [CrossRef] [PubMed]

137. Yoon, J.; Abdelmohsen, K.; Gorospe, M. Posttranscriptional gene regulation by long noncoding RNA. J. Mol. Biol. 2013, 425, 3723-3730. [CrossRef]

138. Maathuis, H.; Kalisch, M.; Bühlmann, P. Estimating highdimensional intervention effects from observational data. Ann. Stat. 2009, 37, 3133-3164. [CrossRef]

139. Le, T.; Hoang, T.; Li, J.; Liu, L.; Liu, H.; Hu, S. A fast PC algorithm for high dimensional causal discovery with multi-core PCs. IEEE/ACM Trans. Comput. Biol. Bioinform. 2016, 16, 1483-1495. [CrossRef]

140. Spirtes, P.; Glymour, C.; Scheines, R. Causation, Prediction, and Search, 2nd ed.; MIT Press: Cambridge, UK, 2000.

141. Pearl, J. Causality: Models, Reasoning, and Inference; Cambridge University Press: New York, NY, USA, 2000.

142. Du, Z.; Fei, T.; Verhaak, R.; Su, Z.; Zhang, Y.; Brown, M.; Chen, Y.; Liu, X. Integrative genomic analyses reveal clinically relevant long noncoding RNAs in human cancer. Nat. Struct. Mol. Biol. 2013, 20, 908-913. [CrossRef]

143. Plaisier, C.; O’Brien, S.; Bernard, B.; Reynolds, S.; Simon, Z.; Toledo, C.; Ding, Y.; Reiss, D.; Paddison, P.; Baliga, N. Causal Mechanistic Regulatory Network for Glioblastoma Deciphered Using Systems Genetics Network Analysis. Cell Syst. 2016, 3, 172-186. [CrossRef]

144. Musa, J.; Aynaud, M.M.; Mirabeau, O.; Delattre, O.; Grünewald, T.G. MYBL2 (B-Myb): A central regulator of cell proliferation, cell survival and differentiation involved in tumorigenesis. Cell Death Dis. 2017, 8, e2895. [CrossRef] [PubMed]

145. Kaiser, J.; Bland, C.; KlinkeII, D. Identifying causal networks linking cancer processes and antitumor immunity using Bayesian network inference and metagene constructs. Biotechnol. Prog. 2016, 32, 470-479. [CrossRef]

146. Tsamardinos, I.; Aliferis, C.; Statnikov, A. Algorithms for large scale Markov Blanket discovery. In Proceedings of the The 16th International FLAIRS Conference, St. Augustine, FL, USA, 12-14 May 2003; pp. 376-380.

147. Kunkle, B.; Yoo, C.; Roy, D. Reverse Engineering of Modified Genes by Bayesian Network Analysis Defines Molecular Determinants Critical to the Development of Glioblastoma. PLoS ONE 2013, 8, e64140. [CrossRef] [PubMed]

148. Odreman, F.; Vindigni, M.; Gonzales, M.L.; Niccolini, B.; Candiano, G.; Zanotti, B.; Skrap, M.; Pizzolitto, S.; Stanta, G.; Vindigni, A. Proteomic studies on low- and high-grade human brain astrocytomas. J. Proteome Res. 2005, 4, 698-708. [CrossRef] 
149. Jung, T.Y.; Choi, Y.D.; Kim, Y.H.; Lee, J.J.; Kim, H.S.; Kim, J.S.; Kim, S.K.; Jung, S.; Cho, D. Immunological characterization of glioblastoma cells for immunotherapy. Anticancer Res. 2013, 33, 2525-2534. [PubMed]

150. Cardoso, L.C.; da S. Soares, R.; de S. Laurentino, T.; Lerario, A.M.; Marie, S.K.N.; Oba-Shinjo, S.M. CD99 expression in glioblastoma molecular subtypes and role in migration and invasion. Int. J. Mol. Sci. 2019, 20, 1137.

151. Holden, J.A.; Townsend, J.J. DNA topoisomerase II-alpha as a proliferation marker in astrocytic neoplasms of the central nervous system: Correlation with MIB1 expression and patient survival. Mod. Pathol. 1999, 12, 1094-1100. [PubMed]

152. Kosti, A.; de Araujo, P.R.; Li, W.Q.; Guardia, G.D.A.; Chiou, J.; Yi, C.; Ray, D.; Meliso, F.; Li, Y.M.; Delambre, T.; et al. The RNA-binding protein SERBP1 functions as a novel oncogenic factor in glioblastoma by bridging cancer metabolism and epigenetic regulation. Genome Biol. 2020, 21, 195. [CrossRef]

153. Cai, C.; Cooper, G.; Lu, K.; Ma, X.; Xu, S.; Zhao, Z.; Chen, X.; Xue, Y.; Lee, A.; Clark, N.; et al. Systematic discovery of the functional impact of somatic genome alterations in individual tumors through tumor-specific causal inference. PLoS Comput. Biol. 2019, 15, e1007088. [CrossRef]

154. Howell, A.; Zheng, J.; Haycock, P.; McAleenan, A.; Relton, C.; Martin, R.; Kurian, K. Use of Mendelian Randomization for Identifying Risk Factors for Brain Tumors. Front. Genet. 2018, 9, 525. [CrossRef]

155. Howell, A.E.; Robinson, J.W.; Wootton, R.E.; McAleenan, A.; Tsavachidis, S.; Ostrom, Q.T.; Kurian, K.M. Testing for causality between systematically identified risk factors and glioma: A Mendelian randomization study. BMC Cancer 2020, 508, 1471-2407. [CrossRef]

156. Drost, J.; Clevers, H. Organoids in cancer research. Nat. Rev. Cancer 2018, 18, 407-418. [CrossRef]

157. Linkous, A.; Balamatsias, D.; Snuderl, M.; Edwards, L.; Miyaguchi, K.; Milner, T.; Reich, B.; Cohen-Gould, L.; Storaska, A.; Nakayama, Y.; et al. Modeling Patient-Derived Glioblastoma with Cerebral Organoids. Cell Rep. 2019, 26, 3203-3211.e5. [CrossRef]

158. Jacob, F.; Salinas, R.D.; Zhang, D.Y.; Nguyen, P.T.T.; Schnoll, J.G.; Wong, S.Z.H.; Thokala, R.; Sheikh, S.; Saxena, D.; Prokop, S.; et al. A Patient-Derived Glioblastoma Organoid Model and Biobank Recapitulates Inter- and Intra-tumoral Heterogeneity. Cell 2020, 180, 188-204.e22. [CrossRef]

159. Yuki, K.; Cheng, N.; Nakano, M.; Kuo, C.J. Organoid Models of Tumor Immunology. Trends Immunol. 2020, 41, 652-664. [CrossRef]

160. Tentler, J.J.; Tan, A.C.; Weekes, C.D.; Jimeno, A.; Leong, S.; Pitts, T.M.; Arcaroli, J.J.; Messersmith, W.A.; Eckhardt, S.G. Patientderived tumour xenografts as models for oncology drug development. Nat. Rev. Clin. Oncol. 2012, 9, 338-350. [CrossRef]

161. Siolas, D.; Hannon, G.J. Patient Derived Tumor Xenografts: Transforming clinical samples into mouse models. Cancer Res. 2013, 73, 5315-5319. [CrossRef]

162. Hidalgo, M.; Amant, F.; Biankin, A.V.; Budinská, E.; Byrne, A.T.; Caldas, C.; Clarke, R.B.; de Jong, S.; Jonkers, J.; Mælandsmo, G.M.; et al. Patient Derived Xenograft Models: An Emerging Platform for Translational Cancer Research. Cancer Discov. 2014, 4, 998-1013. [CrossRef]

163. Vaubel, R.A.; Tian, S.; Remonde, D.; Schroeder, M.A.; Mladek, A.C.; Kitange, G.J.; Caron, A.; Kollmeyer, T.M.; Grove, R.; Peng, S.; et al. Genomic and phenotypic characterization of a broad panel of patient-derived xenografts reflects the diversity of glioblastoma. Clin. Cancer Res. 2020, 26, 1094-1104. [CrossRef]

164. Gao, H.; Korn, J.M.; Ferretti, S.; Monahan, J.E.; Wang, Y.; Singh, M.; Zhang, C.; Schnell, C.; Yang, G.; Zhang, Y.; et al. Highthroughput screening using patient-derived tumor xenografts to predict clinical trial drug response. Nat. Med. 2015, 21, 1318-1325. [CrossRef]

165. Zhao, S.G.; Yu, M.; Spratt, D.E.; Chang, S.L.; Feng, F.Y.; Kim, M.M.; Speers, C.W.; Carlson, B.L.; Mladek, A.C.; Lawrence, T.S.; et al. Xenograft-based, platform-independent gene signatures to predict response to alkylating chemotherapy, radiation, and combination therapy for glioblastoma. Neuro-Oncology 2019, 21, 1141-1149. [CrossRef]

166. Pantel, K.; Alix-Panabières, C. Circulating tumour cells in cancer patients: Challenges and perspectives. Trends Mol. Med. 2010, 16, 398-406. [CrossRef]

167. Kilgour, E.; Rothwell, D.G.; Brady, G.; Dive, C. Liquid Biopsy-Based Biomarkers of Treatment Response and Resistance. Cancer Cell 2020, 37, 485-495. [CrossRef]

168. Pantel, K.; Alix-Panabières, C. Liquid biopsy and minimal residual disease-latest advances and implications for cure. Nat. Rev. Clin. Oncol. 2019, 16, 409-424. [CrossRef]

169. Best, M.G.; Sol, N.; Zijl, S.; Reijneveld, J.C.; Wesseling, P.; Wurdinger, T. Liquid biopsies in patients with diffuse glioma. Acta Neuropathol. 2015, 129, 849-865. [CrossRef] [PubMed]

170. Miller, A.M.; Shah, R.H.; Pentsova, E.I.; Pourmaleki, M.; Briggs, S.; Distefano, N.; Zheng, Y.; Skakodub, A.; Mehta, S.A.; Campos, C.; et al. Tracking tumour evolution in glioma through liquid biopsies of cerebrospinal fluid. Nature 2019, 565, 654-658. [CrossRef] [PubMed]

171. Cha, J.; Lee, I. Single-cell network biology for resolving cellular heterogeneity in human diseases. Exp. Mol. Med. 2020, 52, 1798-1808. [CrossRef] [PubMed] 